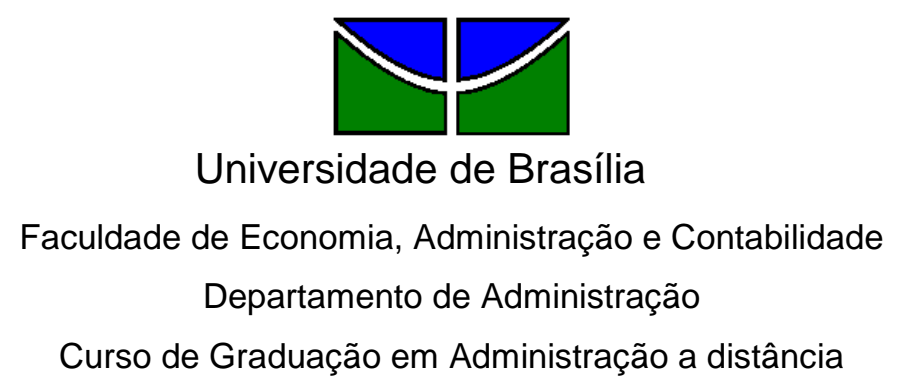

ANTÔNIO WALTER DE CARVALHO RABELO

\title{
Estrutura e Processo de Organizações Virtuais: uma pesquisa com foco em equipes multidisciplinares
}

Brasília - DF 


\section{ANTÔNIO WALTER DE CARVALHO RABELO}

\section{Estrutura e Processo de Organizações Virtuais: uma pesquisa com foco em equipes multidisciplinares}

Monografia apresentada a Universidade de Brasília (UnB) como requisito parcial para obtenção do grau de Bacharel em Administração.

Professor Supervisor: Doutor em Física Aplicada e Computacional, Rildo Ribeiro dos Santos

Professor Orientador: Especialista em Gestão Estratégica, Wildston Silva de Freitas 
Rabelo, Antônio Walter de Carvalho.

Estrutura e Processo de Organizações Virtuais: uma pesquisa com foco em equipes multidisciplinares. Brasil / Antônio Walter de Carvalho Rabelo - Brasília, 2010.

$58 \mathrm{f}$. : il.

Monografia (bacharelado) - Universidade de Brasília, Departamento de Administração - EaD, 2010.

Orientador: Prof. Esp. Wildston Silva de Freitas, Departamento de Administração.

1. Virtualização. 2. Redes estratégicas. 3. Equipes Multidisciplinares.

4. Empresas desenvolvedoras de jogos. I. Título: Subtítulo. 


\title{
ANTÔNIO WALTER DE CARVALHO RABELO
}

\section{Estrutura e Processo de Organizações Virtuais: uma pesquisa com foco em equipes multidisciplinares}

\begin{abstract}
A Comissão Examinadora, abaixo identificada, aprova o Trabalho de Conclusão do Curso de Administração da Universidade de Brasília do aluno
\end{abstract}

\author{
Antônio Walter de Carvalho Rabelo \\ Especialista em Gestão Estratégica, Wildston Silva de Freitas \\ Professor-Orientador
}

Prof. Dr. Rildo Ribeiro dos Santos

Professor-Examinador
Prof. ${ }^{\text {a }}$ Espec. Viviane Moura Martins

Professor-Examinador 


\section{RESUMO}

Este trabalho discorre sobre um tema emergente que é aplicação do conceito de virtualidade em organizações. Virtualidade no mundo dos negócios está ligada à elevação do nível de abstração das interações entre as partes envolvidas com o auxílio de mecanismos tecnológicos, permitindo a configuração de um ambiente mais dinâmico e flexível. Assim, através de uma pesquisa exploratória, (amparada pelo envio eletrônico de questionário quantitativo-qualitativo) em empresas desenvolvedoras de jogos nacionais pôde-se verificar que existe uma tendência de estruturação da virtualização devido ao fato dessas organizações utilizarem grandemente da tecnologia para agilizar a comunicação bem como tendem a formar redes estratégicas com parceiros para concretizar seus projetos. Nesse sentido, a variável humana é muito importante, por isso, o foco da pesquisa está relacionado à interação entre equipes multidisciplinares seja dentro da empresa seja no trato com o mundo externo (parceiros, fornecedores e clientes). Isso motivou a avaliação de como a cultura organizacional influencia na virtualização da empresa e pôde-se constatar que ainda existe uma certa resistência, pois a maturidade e a confiança são fatores que dificultam o estabelecimento de uma organização plenamente virtual. Por fim, buscou-se verificar quais as vantagens obtidas e esperadas pelas empresas que estão usando ou estão planejando usar mais mecanismos virtuais. $\mathrm{E}$ foi possível constatar que as empresas estão interessadas e já começaram a verificar ganhos como a redução de custos, atingir mercados maiores e facilitar o trabalho, e esperam obter maior flexibilidade no trabalho, aumento da capacidade produtiva e catalisação do processo produtivo.

Palavras-chave: Virtualização. Redes estratégicas. Equipes multidisciplinares. Empresas desenvolvedoras de jogos. 


\section{Sumário}

1 INTRODUÇÃO

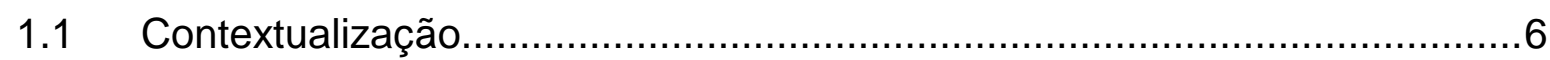

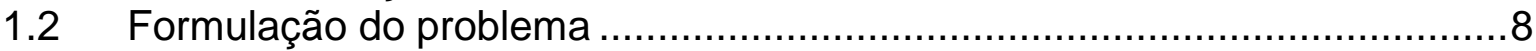

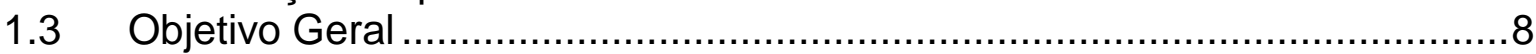

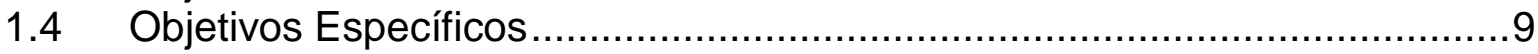

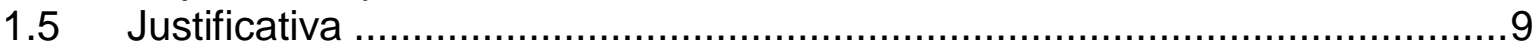

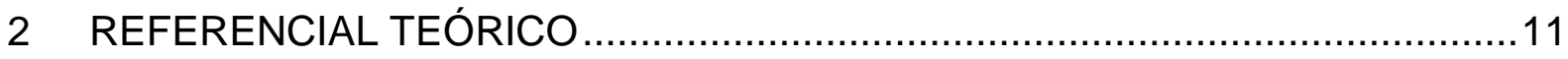

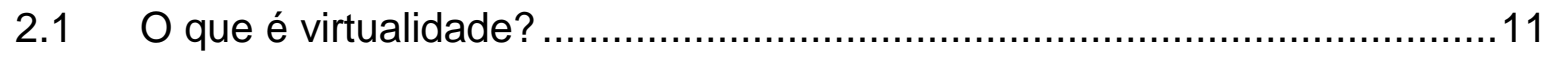

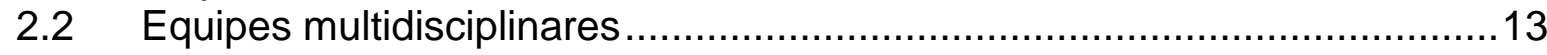

2.3 Argumentos e obstáculos da virtualização .........................................15

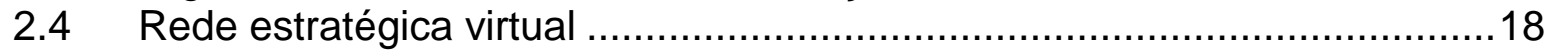

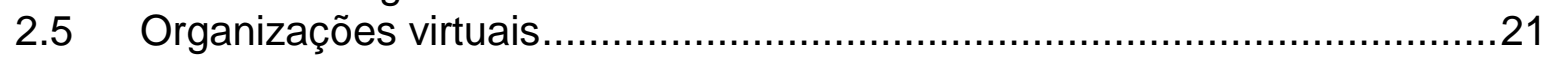

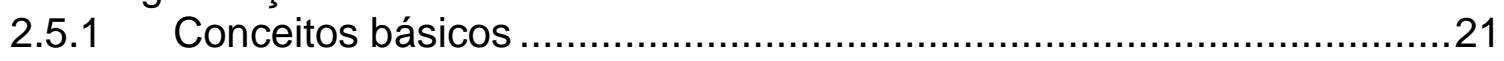

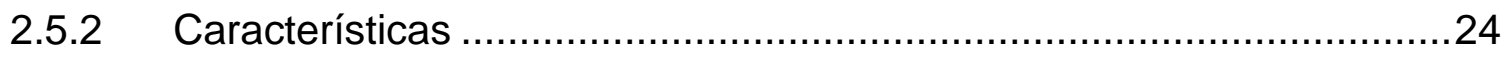

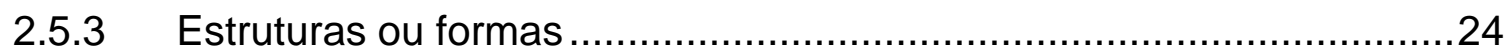

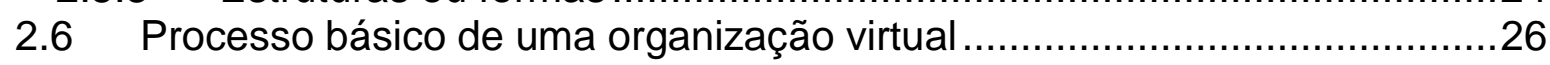

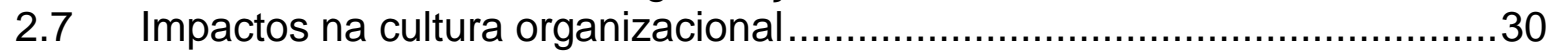

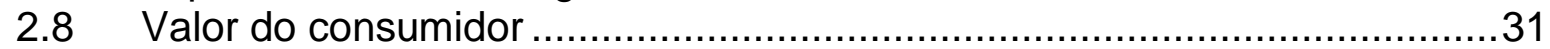

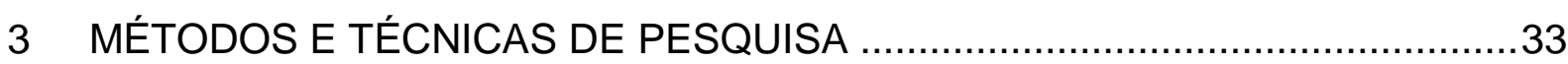

3.1 Tipo e descrição geral da pesquisa.....................................................33

3.2 Caracterização da organização, setor ou área do objeto de estudo ............34

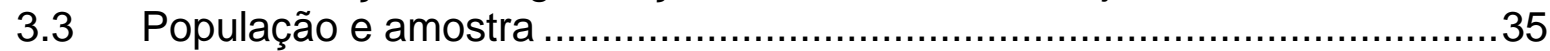

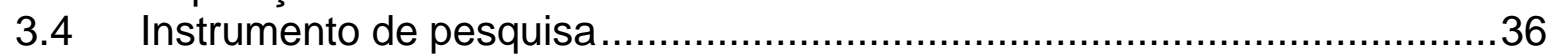

3.5 Procedimentos de coleta e de análise de dados.........................................36

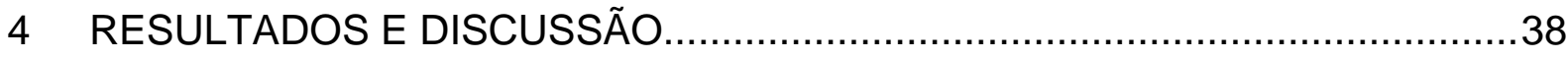

4.1 Caracterização das empresas entrevistadas ...........................................38

4.2 Aspectos de interação entre empresas ..................................................39

4.3 Estruturas físicas ou tecnológicas que permitem usufruir da virtualidade ...40

4.4 Interação entre as equipes multidisciplinares ......................................41

4.5 Aspectos de comunicação com os clientes.........................................42

4.6 Aspectos de comunicação com os fornecedores ..................................42

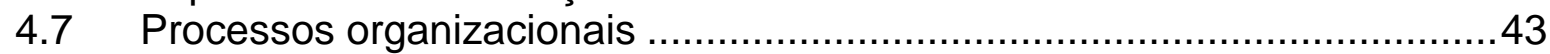

4.8 Perspectivas sobre os aspectos culturais da organização e opiniões acerca das vantagens obtidas e esperadas com o uso da virtualização ...........................45

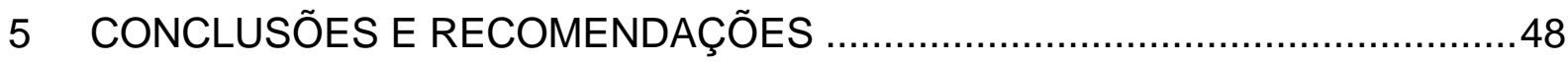

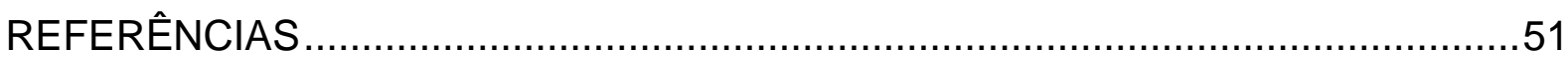

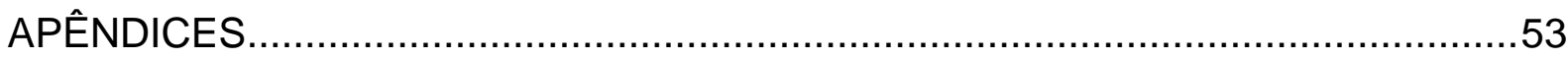

Apêndice A - Questionário de pesquisa ......................................................53 


\section{INTRODUÇÃO}

A virtualização é um fenômeno de permite a um ator atuar com uma força potencial e o avanço da tecnologia tem ajudado, cada vez mais, a tornar essa força potencial em uma realidade concreta para as organizações.

Este trabalho objetiva verificar uma tendência da virtualização em empresas desenvolvedoras de jogos, a fim de entender como essa força potencial está sendo utilizada, uma vez que, são organizações que dependem muito do compartilhamento de informações entre pessoas de diferentes perfis como: programadores, artistas gráficos, músicos, atores, gerentes de parceiras, fornecedores e clientes demandantes do produto ou clientes dispersos no mercado. Todos esses atores auxiliam as empresas desenvolvedoras de jogos na configuração e personalização de seus produtos a partir de interações em forma de redes estratégicas e pode não ser possível um contato físico uma vez que existe uma dispersão geográfica.

Por esse motivo buscou-se na literatura assuntos correlatos para: compreender o conceito de virtualidade, verificar aspectos de interação em equipes multidisciplinares, esclarecer os argumentos e obstáculos na virtualização de empresas, definir o que seriam as redes estratégicas virtuais que podem se configurar na interação entre várias empresas, entender mais profundamente o que seriam organizações virtuais verificando seus processos básicos e sua estrutura a fim de tipificar aquelas empresas e, finalmente, avaliar a questão da cultura organizacional e o valor do consumidor e como estes ajudam a caracterizar e influenciar na virtualização da empresa. Assim, obteve-se argumentos suficientes para avaliar a tendência de virtualização verificando as dificuldades que aspectos culturais em equipes multidisciplinares podem proporcionar e as vantagens obtidas $e$ esperadas com o uso da virtualização.

\subsection{Contextualização}

A crescente globalização tem propiciado mecanismos de comunicação virtuais mais robustos e seguros que propiciam às organizações contratar pessoas capacitadas 
ao redor do mundo. De fato, segundo Agustini (2000), a empresa convencional não terá mais espaço no mercado, pois esse tipo de empresa, que fica atrelado ao local onde está, não terá eficácia. Agustini enfatiza que isso ocorre devido a dois motivos principais: o custo tenderá a ser mais alto do que outras, e a empresa poderá estar longe demais dos clientes. Essa urgência e necessidade em criar mecanismos virtuais decorrem do avanço da globalização:

[...] tudo acontece rápida e simultaneamente, de forma cooperativa, independentemente do lugar do mundo onde tenha ocorrido. No século passado, a confluência entre globalização e avanços tecnológicos revolucionou o processo de criação de valor, notadamente, a partir da transição de uma economia industrial para uma economia baseada na informação. Nesse contexto de grande complexidade, instabilidade e incerteza, as mudanças organizacionais têm sido encaradas como um dos principais meios para se estruturar e explorar o novo mundo dos negócios. (TOLEDO e LOURES, 2006).

Por esse motivo, a administração de projetos em meio virtual com equipes multidisciplinares como a produção de jogos eletrônicos, cinema e animações demandam uma estruturação e um processo de coordenação muito mais complexo que os processos tradicionais. Isso acontece por que o fluxo de informação é mais intenso e distribuído entre as empresas participantes:

Ou seja, o conhecimento e sua gestão, passam a ter valor econômico e serem compreendidos como elementos essenciais ao sucesso organizacional. Neste sentido, [...] o investimento em tecnologia, a maior automação e flexibilidade de estruturas, contratos junto a pessoas, sistemas de produção, enfim, passam a ser diferenciais importantes para a sustentação e crescimento das organizações no mundo moderno. (MELLO et al, 2000).

Uma questão importantíssima está relacionada à comunicação entre as partes em uma organização virtual, pois sem a comunicação não há fluxo de informações e o conhecimento não é retroalimentado seja pelas idéias dos participantes, seja pelas críticas dos clientes, seja pelas experiências dos fornecedores. Cabe então aos gestores virtuais a responsabilidade de, segundo Pitassi e Macedo-Soares (2003), atuar como arquitetos de redes dinâmicas altamente flexíveis, formadas para capturar uma oportunidade de mercado e serem 
dissolvidas assim que se complete a tarefa. Para Hasse (2006) essas redes que compõe a empresa virtual tendem a serem estáveis e compõe empresas independentes com objetivos mútuos.

Dessa forma, esse trabalho visa analisar a tendência de virtualização em empresas da indústria de jogos brasileira que dependem da força de trabalho de várias equipes com focos distintos e que necessitam de uma comunicação mais ágil com parceiros, clientes e fornecedores que cooperam pela concretização de um mesmo objetivo.

\subsection{Formulação do problema}

Dadas as vantagens da virtualidade em propiciar melhor competitividade para as organizações, como tornar a empresa mais flexível e ampliar sua rede de colaboradores, é necessário investigar quais dificuldades as empresas desenvolvedoras de jogos brasileiras possuem na implementação de mecanismos de virtualização. Essas empresas apresentam dificuldades na implementação de mecanismos de virtualização em decorrência da dificuldade de mudanças (ou da falta) da estrutura ou de processos organizacionais?

\subsection{Objetivo Geral}

Verificar a tendência de estruturação da virtualização nas empresas desenvolvedoras de jogos nacionais com equipes multidisciplinares. 


\subsection{Objetivos Específicos}

- Avaliar o cenário nacional do uso de mecanismos de virtualização em empresas desenvolvedoras de jogos brasileiras;

- Identificar fatores de cultura organizacional que dificultam o processo de incorporação de mecanismos de virtualização;

- Identificar as vantagens obtidas com o uso da virtualização nas empresas que já trabalham com esse mecanismo;

- Identificar as vantagens esperadas com o uso da virtualização nas empresas que pretendem usar esse mecanismo;

\subsection{Justificativa}

Essa monografia se justifica pela importância de se compreender um conceito relativamente emergente que é a virtualização empresarial e analisar aspectos estruturais e de processo, caso existam, em empresas desenvolvedoras de jogos brasileiras. Os mecanismos de virtualização influenciam na forma como é executado o controle gerencial dos projetos e essa pesquisa ajudará a avaliar se as empresas estão preparadas para embarcar nesse novo mundo.

A questão da virtualização empresarial parece oferecer um diferencial muito interessante para as empresas que as adotam. Uma vez que se pode receber e dar respostas em um tempo mais curto com o uso da virtualidade. Dessa forma, pode-se clarear a noção de que, o sistema aberto, que é a organização, se torna cada vez mais integrado com o meio externo ao observar a velocidade como se dão as ações tomadas pelos seus concorrentes, as percepções dos clientes e a atuação de seus parceiros.

Nesse contexto a quebra de fronteiras geográficas pode oferecer às empresas que adotam um modelo virtual uma capacidade de ampliar o seu poder no mercado. Isso se deve ao fato de projetos poderem ser realizados em diversas partes do mundo aproveitando-se dos fusos horários para entregar mais 
rapidamente um produto ao cliente. Por isso, a investigação de como esse controle gerencial pode ser feito é importante e como isso pode ser impactado pelas questões de cultura organizacional, na estrutura e nos processos organizacionais. 


\section{REFERENCIAL TEÓRICO}

\subsection{O que é virtualidade?}

Virtual não significa impossibilidade, na verdade algo virtual apenas não existe como realidade mas tem potencial e possibilidade de ser exercido em termos reais em um período futuro. Mello (2000) exemplifica esse conceito explicando que o virtual tende a atualizar-se, assim como uma árvore está virtualmente presente na semente. Dessa forma, o que é virtual não é oposto do que é real mas sim do que é atual. $E$, por esse motivo, as possibilidades de mudança de algo virtual permitem qualificá-lo também como algo dinâmico:

O virtual também pode ser compreendido como qualquer coisa aparente, sem definição prefixada que se contrapõe com o real ou o real absoluto. [...] Assim, a virtualização é uma mutação de identidade, um deslocamento do centro de gravidade do objeto considerado. (MELLO et al, 2000).

Outros autores também concordam com a idéia de potência dinâmica como sugerido pela conceituação de Agustini (2000): "O virtual possui a potencialidade para se atualizar sem passar à concretização efetiva ou convencional".

Esses conceitos levam a definir melhor o que seria virtualidade no meio empresarial. A virtualidade das organizações tende a caracterizar um ambiente dinâmico no qual existe uma proposta ou modelo de trabalho subjetiva que pode se contorcer para executar tarefas ad-hoc. Para Pitassi e Macedo-Soares (2003), a virtualidade significa uma manifestação subjetiva e reflexiva do objeto concreto, ao qual ela está intima e dialeticamente ligada. Dessa forma, a manifestação subjetiva pode ser alterada conforme necessário para que o objeto concreto que ela representa tenha uma ação determinada em um período futuro. Por esse motivo alguns autores, como Castells (1999), Chandrashekar e Schary, 1999), citados por Pitassi e Macedo-Soares (2003) enfatizam que: "a virtualidade está relacionada ao 
desenvolvimento de unidades operacionais interligadas por meio de intensas comunicações mediadas por computadores".

A comunicação por meio de computadores auxilia na definição mais dinâmica dos processos de trabalho de uma organização. Sem ela não seria possível coordenar o fluxo de informações em uma organização em tempo hábil para refletir sobre o processo propriamente dito de forma a alterá-lo para necessidades específicas. O uso de mecanismos tecnológicos para comunicação é extremamente importante pois sem eles seria custoso mudar.

A comunicação virtual leva a uma nova forma de interação social que são as comunidades virtuais, esse conceito é importante para a questão da virtualidade pois permite definir mecanismos de organização interativa ad-hoc. Isso é clarificado através da conceituação de comunidades virtuais descrita por Pitassi e MacedoSoares (2003): "Por comunidade virtual entende-se uma rede eletrônica de comunicação interativa auto-definida, organizada em torno de um interesse ou finalidade compartilhados".

Destarte, as empresas virtuais ou que possuem alguns mecanismos de virtualização podem virtualmente ser representadas como alianças entre empresas, ou serem pequenas empresas que utilizam serviços de terceirizadas, ou cooperativas. Enfim, uma empresa virtual deve estar em constante comunicação com outras empresas parceiras o que leva a criação de redes virtuais que influenciam na estratégia de negócio de todas as empresas colaboradoras. Pitassi e Macedo-Soares (2003) enfatizam que a diferença entre uma rede estratégica tradicional e uma rede virtual é o grau em que as transações de negócio são realizadas por meio da Internet. O que reforça a necessidade do uso da tecnologia como ferramenta de virtualização empresarial.

Essa tendência foi naturalmente influenciada pela própria globalização mundial que trouxe à tona uma cultura de compartilhamento de informações. Isso pode ser verificado com a concordância de alguns autores quando explicitam que:

[...]os mecanismos de auto-governança, a cultura de compartilhamento, os fatores motivacionais que se reforçam, comuns aos movimentos ligados aos sistemas de código aberto (open-source), sinalizam possíveis caminhos para a virtualidade nas organizações. (PITASSI e MACEDO-SOARES, apud MARKUS, MANVILLE e AGRES, 2003). 
Entretanto empresas interessadas em mecanismos de virtualização devem se atentar para as questões de cultura organizacional, pois, conforme Pitassi e Macedo-Soares (2003), a mudança de protocolo cultural provavelmente se configure no maior desafio em direção à virtualidade, já que ela envolve modelos mentais, cuja alteração é lenta e complexa.

\subsection{Equipes multidisciplinares}

Multidisciplinar como os próprios radicais semânticos sugerem quer dizer muitas disciplinas. É algo que envolve a atuação de diversas áreas do conhecimento para alcançar um determinada finalidade. Exemplos de equipes multidisciplinares mais claros de visualizar estão relacionados à trabalhos que envolvem técnica e arte como desenvolvimento de jogos, cinema e animações gráficas, sendo que o produto final depende diretamente da atuação coordenada das disciplinas. Esse trabalho visa focar em equipes multidisciplinares que possuam essa característica: quando envolvem trabalhos extremamente técnicos e objetivos e trabalhos extremamente artísticos e subjetivos. Barros et al (2009) explica que o conceito de equipes multidisciplinares está diretamente ligado à variedade de habilidades e formações de seus integrantes, além do alto grau de interdependência entre suas atividades.

Em empresas virtuais, a coordenação dessas equipes é algo que deve ser realizado com extremo cuidado, pois a comunicação entre as partes é vital para a execução do trabalho tendo em vista que:

uma equipe multidisciplinar se caracteriza como um grupo de pessoas com alto grau de interdependência, que aplica diferentes habilidades, oriundas de diferentes áreas, a fim de assegurar a efetiva entrega de um objetivo organizacional comum. (BARROS et al, apud HOLLAND, 2009).

A virtualidade de uma organização tende a reduzir o contato pessoal entre as partes envolvidas na execução do trabalho. Em geral, empresas desenvolvedoras de jogos eletrônicos, por exemplo, tendem a contratar serviços especializados do meio artístico como orquestras sinfônicas, atores e artistas plásticos, que são providos por outras empresas. Por isso, a importância da comunicação, tendo em vista que segundo Barros et al (2009) a adoção de equipes multidisciplinares 
envolve também dificuldades, ligadas principalmente à comunicação e coordenação do grupo. Isso se deve pelo simples fato de que cada empresa ou cada profissional estar acostumado com um certo modo de trabalho.

No caso da virtualidade alguns autores concordam que usar meios tecnológicos permitem melhor colaboração, mas a redução do contato social pode criar mecanismos muito formais que podem prejudicar o trabalho. Por isso, é importante enfatizar que na comunicação virtual entre empresas há uma:

predominância da utilização de recursos tecnológicos como infra-estrutura de redes de comunicação e software (aplicativos de comunicação para troca de mensagens, texto, imagens, vídeo), tais como correio eletrônico, fóruns, grupos de discussão on-line. Estes recursos são apresentados por Pinochet, Barbosa e Silva (2005) como os principais viabilizadores de redes colaborativas interorganizacionais.(CUNHA e MEDEIROS, 2007)

Entretanto, pode parecer um paradoxo em empresas multidisciplinares que utilizam virtualização, pois de um lado as equipes multidisciplinares precisam de um alto grau de interdependência e de outro a necessidade de virtualização expressa a redução dos contatos pessoais através da comunicação virtual para dar mais flexibilidade à empresa.

Cunha e Medeiros (2007) explicam que o uso exclusivo de meios que reduzem a necessidade de contatos pessoais na rede reforça, novamente, a ênfase na rede formal, reduzindo as oportunidades de desenvolver relações mais pessoais entre os membros.

A redução de relações pessoais torna a empresa que usa mecanismos de virtualização mais flexível uma vez que poderá virtualizar o uso de parceiros de negócio adaptando-se a um serviço específico. Entretanto aqueles autores ainda apontam para um cuidado importante que deve principalmente ser aplicado em equipes multidisciplinares, pois a coordenação das mesmas deve estar alinhada com os objetivos estratégicos direcionados ao serviço prestado, que é:

[...]cautela quando da utilização apenas de redes formais. Tal dependência pode apresentar problemas tanto de eficiência quanto de eficácia, por causa de sua lentidão, a possibilidade que oferece para eliminação de informações por superiores hierárquicos, e a falta de coerência. (CUNHA e MEDEIROS, 2007). 


\subsection{Argumentos e obstáculos da virtualização}

Segundo Pitassi e Macedo-Soares (2003) as empresas tradicionais que pretendem utilizar mecanismos de virtualização podem estender seus negócios por meio de um novo canal de e-business, o qual mantém laço estreito com o modelo físico de negócio. Dessa forma, a formulação de negócios em meio eletrônico (e-business) permite um maior fluxo de informações entre as parcerias, pois:

As organizações têm acesso a um grande volume de informações, disponível a todas elas, o que pode ser uma vantagem competitiva para algumas e funcionar como barreira para outras[...] observação que chama a atenção para a maneira que se operacionaliza um sistema para a inteligência empresarial. (CUNHA e MEDEIROS, 2007).

Para que o fluxo de informações não se torne uma barreira para as empresas participantes da relação de um negócio virtualizado elas devem investir pesado em tecnologia da informação ( $\mathrm{TI})$ a fim de manter em foco as estratégias definidas para a rede virtual (as redes virtuais podem ser chamadas de REVS ou redes estratégicas virtuais). Essa necessidade de investimento em TI foi verificada pelos autores Pitassi e Macedo-Soares em seu trabalho onde levantaram, no cenário nacional, que:

[...]os executivos das empresas líderes no Brasil consideraram que, no futuro, os maiores investimentos de tempo e dinheiro, no que concerne às $R E V s$, serão dedicados à construção de apropriada infra-estrutura de TI, à integração da base legada de sistemas operacionais ao e-business e à adequação da cultura organizacional às REVs. (PITASSI e MACEDO-SOARES, 2003).

A idéia de forte comunicação e interação entre as empresas através do $e$ business criam um cenário com algumas vantagens e desvantagens ao se utilizar mecanismos de virtualização representadas por argumentos e obstáculos. E como é um meio de intensa interação, Cunha e Medeiros (2007) ainda explicam que as vantagens competitivas duram apenas até que os competidores as copiem ou descubram táticas de manobra para as mesmas. 
Agustini (2000) aponta alguns argumentos para se utilizar a virtualização de empresas:

- Compartilhamento de recursos: Dada a agilidade que o mercado demanda, as empresas compartilham mais recursos utilizando suas habilidades principais para conquistar oportunidades de mercado que se apresentam de maneira rápida e temporária.

- Compartilhamento de conhecimento: Dada a impossibilidade de qualquer empresa manter todo o conhecimento de como atuar em um mercado global. As empresas se associam para complementarem suas necessidades de tal forma que haja sinergia entre as partes.

- Rateio de custo: Fator motivador para criação de organizações virtuais, pois o custo é um limitador na viabilização de novos produtos ou projetos, inibindo a competitividade no mercado.

- Cadeia de suprimentos: A economia atual está baseada nos sistemas de informação e na economia de serviços que aumentam a rentabilidade das empresas. Dessa forma, uma empresa atuando isoladamente não terá mais espaço dentro da economia moderna.

- Agilidade: Exigências cada vez mais específicas, complexas, personalizadas e imediatas do mercado consumidor forçam as organizações a diminuírem o ciclo de vida do produto. Portanto, a agilidade das comunicações e troca de informações é essencial.

- Acesso a mercados globais: Os participantes da organização virtual terão a capacidade de usufruir de um mercado global e mais abrangente.

- Sistemas de gerenciamento corporativos são antiquados: Recursos computacionais e de telecomunicações realizam melhor as tarefas que antes precisavam de controle e gerenciamento de pessoas. Dessa forma, essas estruturas não são mais necessárias atualmente.

- Soluções globalizadas: A potencialidade de conseguir soluções parciais traz mais velocidade ao processo de agregação do produto final. Essas soluções parciais deixam de ser locais, pois são realizadas através de parceiros que estão em qualquer lugar do mundo. 
- Sistemas de produção antiquados: Os modelos conceituais de Ford e Taylor estão ultrapassados. Os japoneses têm demonstrado que as novas metodologias de produção permitem um gerenciamento antecipado dos estoques e dos pedidos dos clientes.

- Produtividade com qualidade: A concentração de trabalho nas empresas que dominam a tecnologia, deixando para os parceiros outros trabalhos em que o domínio da técnica não é seu cotidiano, aumenta substancialmente a qualidade dos produtos e serviços.

- Informação sozinha não melhora produtividade: Os sistemas são ainda baseados em conceitos contábeis, que nunca foram revisados com profundidade e não contribuem para a produtividade, principalmente se levar em conta a proporção de investimentos efetuados com a tecnologia da informação.

- Competitividade: O somatório dos esforços acima conduzem a uma posição de liderança competitiva que é atualmente a preocupação predominante na estratégia de crescimento das empresas modernas.

Já Hasse (2006) aponta alguns obstáculos à implantação das organizações virtuais:

- Infra-estrutura insuficiente: insuficiência de infra-estrutura básica e de tecnologia da informação para integrar a estrutura virtual;

- Falta de metodologias: falta de metodologias específicas e eficazes para a gestão de organizações virtuais;

- Mecanismos legais: existe a necessidade de desenvolvimento de mecanismos legais e jurídicos de contratação;

- Cultura organizacional: questões sócio-culturais que dificultam o trabalho em alianças;

- Despreparo do administrador: pela falta de experiências e técnicas de gestão de empresas em rede;

- Insegurança no uso da tecnologia: como a falta de segurança na utilização de documentos eletrônicos; 
- Falta de confiança: principalmente no quesito de compartilhamento de informações entre empresas que atuam conjuntamente para atender a uma demanda de mercado.

\subsection{Rede estratégica virtual}

Como já se pôde perceber a necessidade de comunicação entre as empresas, para mutuamente angariarem mais competitividade nos mercados modernos, perfazem a necessidade da definição de uma rede colaborativa. Por isso, o conceito de redes estratégias virtuais é importante para este estudo. Mas primeiro é necessário conceituar o que é uma rede. Para Cunha e Medeiros (2007) redes seriam estruturas abertas capazes de expandir de forma ilimitada, integrando novos nós, desde que consigam comunicar-se compartilhando os mesmos códigos de comunicação. Dessa forma, é necessário algum tipo de protocolo para que a comunicação se estabeleça de forma coerente. No caso de redes estratégicas virtuais esse protocolo é baseado em contratos sociais, de tal forma, que a REV é uma rede social também. Cunha e Medeiros (2007) citam Nelson (1984) que define redes sociais como conjuntos de contatos que ligam vários atores.

É importante notar que a interação entre empresas em uma organização virtual é definida pelo contexto institucional da organização virtual. Conforme explicitam Pitassi e Macedo-Soares (2003) : "[...]as redes resultam de complexas influências de contexto institucional, social e tecnológico, o que torna maniqueísta qualquer tentativa de imposição de regras genéricas de adesão".

Se tudo for corretamente coordenado pela organização virtual muitos benefícios serão alcançados. Cunha e Medeiros (2007) explicam que os ambientes de trabalho virtuais são uma conseqüência das estruturas em rede, trazendo benefícios como aumento de produtividade, maiores lucros e diminuição de custos. Isso corrobora alguns dos argumentos apresentados por Agustini (2000) descritos anteriormente.

Em relação à estratégia, Pitassi e Macedo-Soares (2003) explicam que é um mecanismo que traz coerência e direção às ações e decisões de uma organização, especialmente para alocar e alavancar os recursos necessários para melhorar e sustentar o seu desempenho. Para isso é necessário que a gestão da estratégia 
seja calcada em um processo interativo, conforme explicitado por Pitassi e MacedoSoares (2003): "Gestão estratégica é considerada um processo interativo, por meio do qual as estratégias são criadas, formuladas e implementadas via [...] um conjunto de benefícios, diferentes daqueles oferecidos pelos concorrentes".

Pitassi e Macedo-Soares concordam com outros autores quanto ao conceito de redes estratégicas quando explicam que:

De acordo com Gulati, Nohria e Zaheer (2000,p.203), uma rede estratégica refere-se: "ao conjunto de relacionamentos de uma empresa, tanto os horizontais quanto os verticais, com outras organizações - sejam elas fornecedores,clientes, concorrentes, ou outras entidades - incluindo relacionamentos que atravessam indústrias e países. [Esses] são compostos de laços inter-organizacionais duradouros, [....] de significância estratégica para as empresas envolvidas neles, e incluem alianças estratégicas"(PITASSI e MACEDO-SOARES, 2003)

Por esse motivo a comunicação entre as partes é muito importante. Cunha e Medeiros (2007) enfatizam que a comunicação interpessoal é uma parte importante do processo de interação, podendo ser considerada um elemento processual de relacionamentos e redes. E Pitassi e Macedo-Soares complementam ao citar Galaskiewicz e Zaheer (1999) explicando que uma rede que envolva mais atores e laços, e que tenha maior flexibilidade nos mecanismos de coordenação, pode ampliar sobremaneira sua capacidade de geração de conhecimento o que implica um potencial de gestação de proposições de valor mais ricas e variadas. Dessa forma, as redes estratégicas são redes sociais em que existe uma coordenação bem definida de forma a proporcionar flexibilidade de interação entre as partes interdependentes. Nesse caso, as partes não necessariamente podem ser os parceiros cotidianos, mas algum parceiro que consiga atender às requisições da rede estratégica tendo em vista que a comunicação interpessoal é um elemento processual do relacionamento em redes.

Pitassi e Macedo-Soares (2003) enfatizam, citando outros autores, que nos relacionamentos em redes estratégicas virtuais a hierarquia, o poder e os contratos podem ser suplantados nos modelos de gestão por: 
- mecanismos de governança relacional, cuja dimensão central é a confiança, construída a partir de estruturas normativas e sociais (Achrol e Kotler, 1999);

- um novo código cultural adequado à virtualização, de acordo com o qual as firmas individuais estão preparadas para encontros efêmeros e para a construção de estratégias ad-hoc por meio do compartilhamento de recursos com outras firmas (Castells, 1999), sem que seja necessária uma fase de socialização.

Esses mecanismos de governança relacional são potencializados, como já abordado anteriormente, pelo uso de recursos de TI. Cunha e Medeiros (2007) citando Pinochet, Barbosa e Silva (2005) exemplificam os principais recursos de tecnologia de informação e comunicação utilizados para viabilizar redes colaborativas inter-organizacionais como: a infra-estrutura de redes de comunicação (principalmente internet pública) e recursos de software, ou aplicativos de comunicação para troca de mensagens, texto, imagens, vídeo e som tais como email, chat, vídeo-conferência, fóruns, grupos de discussão on-line e VolP.

Essa necessidade da TI é corroborada por Sakuda e Vasconcelos (2005) quando citam Boudreau et al (1998) e Ghemawatt (2001) ao destacar o uso da TI para aumentar a competitividade da empresa, de tal forma a superar as barreiras temporais e espaciais de empregados e parceiros de negócios mostrando que existem diversas dimensões de distância (cultural, administrativa, geográfica e econômica) que afetam de formas diferenciadas as empresas.

Em suma, conclui-se que as redes estratégicas virtuais necessitam obrigatoriamente de mecanismos tecnológicos para seu perfeito funcionamento. As organizações virtuais se valem dessas $R E V s$ para adquirir maior competitividade no mercado e desfrutar os benefícios do compartilhamento de conhecimento e recursos. Hasse (2006) corrobora esse argumento quando relata que:

As tecnologias da informação e comunicação permitem a criação de empresas que atuam em rede dinâmica estratégica (organizações virtuais) sem as limitações das amarras espaço-temporal em seu relacionamento. Toda a logística de projeto, fabricação, produção e entrega de produtos pode ser realizada por parceiros em um grande consórcio ou outra forma que viabilize as operações em rede. Nesse sentido, as organizações virtuais podem influenciar 
fortemente a estruturação dos processos de trabalho, de forma individual ou na forma como as pessoas trabalham em conjunto. (HASSE, 2006).

\subsection{Organizações virtuais}

\subsubsection{Conceitos básicos}

Segundo Hasse (2006) o conceito de Organização Virtual é recente e foi introduzido por Mowshowitz (1986), como sendo um novo modelo organizacional, sendo composta por uma rede relativamente estável de empresas independentes, que objetivam participar das cooperações entre empresas para aproveitamento de novas oportunidades de negócio.

No seu trabalho, Hasse(2006) define que as organizações virtuais consistem de três elementos organizacionais integrados:

- A plataforma virtual: que têm foco em preparar as condições necessárias para a formação das empresas virtuais;

- O net-broker: ou gestor do ambiente virtual;

- A empresa virtual: que é composta por uma rede relativamente estável e dinâmica de empresas independentes que objetivam participar das cooperações.

Toledo e Loures (2006) também citando Mowshowitz (1997a) explicam que gerenciar uma organização virtual é gerenciar o processo de alocação de recursos concretos, atendendo a requisitos abstratos. Essa visão é uma afirmativa à característica de flexibilidade da organização virtual, uma vez que a organização não depende das empresas concretas mas de empresas que executem o requisito abstrato. Esses autores ainda concordam com Mowshowitz quando verificam que a organização virtual pode ser entendida como a união de três vetores interdependentes:

- Interação com o cliente: o que envolve a experimentação à distância e a personalização de produtos e serviços e a criação e manutenção de comunidades de clientes; 
- Processos organizacionais internos: para aquisição de módulos que irão compor um produto, são reorganizados os processos interdependentes para prover serviços personalizados a um cliente e integração virtual com fornecedores da rede de negócios da qual a empresa faz parte para finalizar o produto ou serviço;

- Processos interorganizacionais: necessários para distribuição de tarefas entre equipes distantes entre si. A meta a ser alcançada é dividida em tarefas que são alocadas a equipes de empresas parceiras. A integração entre essas organizações é feita por ferramentas de groupware para que os grupos envolvidos possam compartilhar informações e conhecimentos. Essa soma de conhecimentos agrega valor e torna a organização virtual mais efetiva do ponto de vista organizacional.

Toledo e Loures (2006) ainda sintetizam, a partir dos estudos de Barcia e Steil (1999), a evolução das organizações virtuais em um quadro (ilustração 1) que explica os três vetores e estágios principais das organizações virtuais.

\begin{tabular}{|c|c|c|c|}
\hline \multirow{2}{*}{$\begin{array}{c}\text { VETORES } \\
\text { E CARACTERISTICAS }\end{array}$} & \multicolumn{3}{|c|}{ ESTAGIOS } \\
\hline & Estágio 1 & Estágio 2 & Estágio 3 \\
\hline $\begin{array}{l}\text { Interação com o } \\
\text { consumidor }\end{array}$ & $\begin{array}{l}\text { produtos e serviços são } \\
\text { experimentados a } \\
\text { distância }\end{array}$ & $\begin{array}{c}\text { Personalização } \\
\text { dinâmica de produtos e } \\
\text { serviços }\end{array}$ & Comunidades virtuais \\
\hline Suprimentos virtuais & $\begin{array}{l}\text { Terceirização de } \\
\text { módulos e de } \\
\text { componentes padrões }\end{array}$ & $\begin{array}{c}\text { Interdependência de } \\
\text { processos }\end{array}$ & Coalização de recursos \\
\hline Conhecimento virtual & $\begin{array}{c}\text { Tecnologia de gestão } \\
\text { de tarefas }\end{array}$ & $\begin{array}{l}\text { Conhecimento como } \\
\text { patrimônio da } \\
\text { organização }\end{array}$ & $\begin{array}{l}\text { Utilização do } \\
\text { conhecimento de } \\
\text { comunidades de } \\
\text { profissionais }\end{array}$ \\
\hline Alvo & Tarefas & Organização & Interorganização \\
\hline Objetivos de desempenho & $\begin{array}{c}\text { Melhorar a eficiência } \\
\text { operacional }\end{array}$ & $\begin{array}{c}\text { Acrescentar valor } \\
\text { econômico }\end{array}$ & $\begin{array}{l}\text { Sustentar a inovação e } \\
\text { o crescimento }\end{array}$ \\
\hline $\begin{array}{l}\text { lustração 1: Org } \\
\text { VENKATRAMAN e H }\end{array}$ & $\begin{array}{l}\text { hizações virtuais } \\
\text { VDERSON,2006) }\end{array}$ & (TOLEDO & LOURES, \\
\hline
\end{tabular}

Basicamente esse quadro mostra que a interação com o consumidor cria novas oportunidades e desafios, pois: em um primeiro momento os produtos são experimentados virtualmente (à distância) o que permite maior controle dos pedidos 
do cliente; em um segundo momento os produtos são meras especificações que podem ser personalizadas de acordo com as necessidades e perfil do cliente; em um terceiro momento, a organização virtual pode se valer da criação e manutenção de uma comunidade virtual de onde poderão ser disseminados aspectos comportamentais, idéias e críticas dos consumidores que são informações valiosas para classificação de mercado e atendimento de expectativa dos clientes.

Outro ponto é relacionado aos suprimentos virtuais que se refere à capacidade da organização de participar de redes de fornecedores: em um primeiro momento as organizações virtuais podem se valer do uso eficiente da terceirização para a criação das soluções parciais; em um segundo momento poderá terceirizar processos importantes para o negócio a fim de melhorar a eficiência e ratear os custos; e, no terceiro momento a organização virtual estará envolvida em uma rede dinâmica onde nenhum dos participantes tem condições de operar isoladamente representando componentes da rede que possuem um portfólio de capacidades bem definidas. Dessa forma, os participantes são capazes de se relacionar mais facilmente com as outras organizações de tal forma a suprir as necessidades das outras.

Finalmente, no terceiro ponto (ou vetor) o conhecimento virtual é um incentivo à disseminação do conhecimento para além das fronteiras da organização, sendo que: em um primeiro momento a gestão de tarefas por meio da tecnologia capacita a organização a distribuir mais facilmente os serviços entre as participantes através do uso de videoconferências, intranet, comunicadores de mensagens entre outros recursos tecnológicos; em um segundo momento, ocorre o compartilhamento do conhecimento coletivo entre as unidades de trabalho tornando-o um patrimônio da organização virtual; e, em um terceiro momento esse conhecimento é transportado além das fronteiras organizacionais com o uso das comunidades de especialistas.

Cada estágio ou momento objetiva aumentar o desempenho da organização virtual, nos estágios iniciais esse objetivo está relacionado às tarefas da empresa de tal forma a melhorar a eficiência operacional. Nos segundos estágios a ênfase é a organização da estrutura da empresa de forma a acrescentar maior valor econômico à mesma. $E$ finalmente nos terceiros estágios a ênfase é na interação entre os participantes com o propósito de sustentar a inovação e o crescimento. 


\subsubsection{Características}

Sobre as organizações virtuais Hasse (2006) define suas principais características:

- São redes temporárias de indivíduos, pequenas empresas ou partes de corporações maiores que se constituem com uma finalidade específica (como por exemplo, desenvolver um produto);

- São constituídas por participantes que não se localizam em um escritório central, mas cada um deles está em um local distinto;

- Colocam ênfase nas competências centrais de cada parte envolvida, o que significa que todos aqueles fazem aquilo que sabem fazer bem;

- Apóiam-se fortemente na comunicação via tecnologias de informação e comunicação;

- Não possuem necessariamente uma estrutura legal comum;

- Atuam sobretudo através da auto-gestão e auto-responsabilização, algo que é possível pela existência de uma meta comum a ser seguida;

- Apresentam uma única identidade aos clientes, isto é, os produtos e/ou serviços são disponibilizados no mercado tal e qual a organização agisse como uma empresa tradicional.

\subsubsection{Estruturas ou formas}

As organizações virtuais possuem cinco formas de estruturação segundo as pesquisas de Toledo e Loures (2006) referenciadas dos trabalhos de Quinn, Anderson e Filkenstein (2001). Nesse trabalho serão explicitadas uma síntese dessas estruturas que serão importantes para a definição tipológica das organizações virtuais foco do trabalho. Dessa forma, as organizações virtuais podem ser classificadas em:

- Organização "infinitamente" plana: caracterizada pela expansibilidade ilimitada. Existe um centro de comando que possui profundo conhecimento do negócio do qual fluem as informações para as empresas participantes. Dessa forma, os participantes dificilmente 
precisam comunicar entre si, podendo operar independentemente. Exemplos são: redes de fast-food, corretoras de valores e empresas aéreas;

- Organização invertida: caracterizada pelo fluxo de informações partir dos participantes da organização virtual. Dessa forma, não há um centro de controle que domina a informação, ou seja, é totalmente descentralizado. Nesse caso existe uma estrutura de suporte que provê logística ou suporte aos participantes, aliviando-os ao máximo dos detalhes administrativos. Exemplos são hospitais, clínicas médicas, empresas de consultoria em engenharia;

- Organização "teia de aranha": caracterizada pelo fluxo de informações em grafo. Cada vértice da organização virtual pode emitir ordens para outros vértices. Não há hierarquia interferente ou centro emissor de ordens. O conhecimento está distribuído na rede. Esse tipo de rede oferece vantagem seletivas em ambientes altamente competitivos por que podem acomodar, ao mesmo tempo, alta especialização, múltiplos locais geográficos e foco em um único problema. Exemplos são grupos de pesquisa entre universidades, consórcios de bibliotecas e grupos de ação política;

- Organização aglomerada: .é organizada como "teia de aranha" só que existem centros agrupadores de conhecimento que realizam tarefas relativamente permanentes ou que requerem profunda competência em áreas específicas. Diferentemente das organizações "teia de aranha" há uma clara autoridade para a tomada de decisões. Exemplos são empresas em fusão, aquisição e novos negócios.

- Organização "raios de sol”: caracterizada como uma rede interorganizacional na qual, por razões especiais, as unidades organizacionais estão sob a mesma propriedade compartilhada. O conhecimento está dividido entre as participantes, enquanto que existe um centro que retém conhecimentos profundos ou básicos em alguma tecnologia comum. Dessa forma, o centro é a essência da competência intelectual enquanto que as participantes são o local de conhecimentos especializados de mercado e de produção. Exemplos são estúdios de cinema e os grupos de capitalistas empreendedores. 
Para este trabalho em as organizações "raios de sol" parecem fazer mais sentido por agruparem participantes com capacidades distintas resultando em uma rede de equipes multidisciplinares que trabalham para desenvolver um mesmo produto ou serviço. Também, apontam para um centro de comando que detém a competência intelectual. O que permite caracterizar tipologicamente as empresas de jogos eletrônicos, estúdios de cinema e animação.

\subsection{Processo básico de uma organização virtual}

As organizações virtuais são eficientes por dependerem de requisições do cliente e não da previsão de demanda de mercado. Conforme afirmam Pitassi e MacedoSoares (2003) em:

No modelo industrial típico, a empresa verticalizada empurrava a produção para o mercado a partir de um padrão interno relativamente rígido de configuração de recursos. No modelo virtual [...] a configuração dos recursos passa a ser definida a partir das necessidades do cliente. (PITASSI e MACEDO-SOARES, 2003).

Para que isto ocorra de forma eficiente, o administrador da organização virtual deve conhecer as competências esperadas das diferentes empresas. Hasse (2006) afirma que o Gestor Virtual conhece as competências de diferentes empresas e possui em profundo conhecimento sobre o mercado. Ao identificar uma oportunidade no mercado, ele a associa às competências necessárias e entra em contato com as empresas. Dessa forma, o gestor virtual é o coordenador da empresa virtual pois possui a capacidade de operacionalizá-la e acompanhá-la para que atinja um conjunto de objetivos estratégicos. Hasse (2006) ainda comenta que o gestor virtual deve se certificar da dissolução da empresa virtual ao final do processo. Por esse motivo, configura-se a existência de um ciclo de vida da organização virtual.

Agustini (2000) expõe a proposta de Mickler (2000) para o ciclo de vida das organizações virtuais, composta de cinco fases descritas na ilustração 2. 


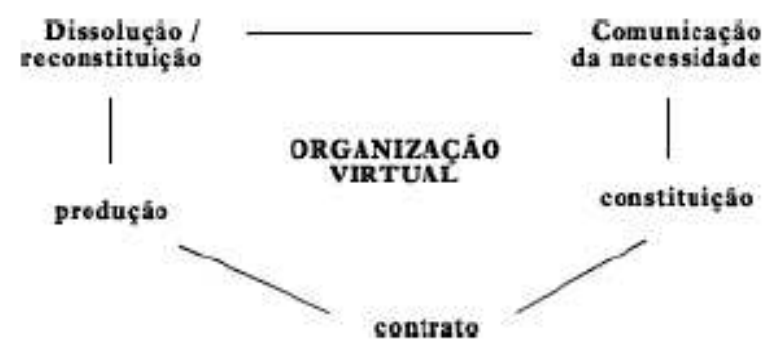

Ilustração 2: Ciclo de vida da organização virtual (AGUSTINI apud MICKLER, 2000)

Nesse modelo as organizações virtuais passam por cinco fases principais, as quais o gestor virtual deve estar atento para concretizar os objetivos estratégicos definidos.

- Comunicação da Necessidade: a organização ou os participantes inteiram-se da demanda por um produto ou serviço especializado e através de meios eletrônicos ou não faz a organização virtual perceber a demanda;

- Constituição: As capacidades humanas, financeiras, materiais e de capital são avaliadas. As competências principais são comparadas com os requisitos específicos dos consumidores. Recursos adicionais, que forem necessários, são localizados com o uso de tecnologias da informação. Uma união pouco coesa é formada com a função de dar ponto de partida para direcionar as necessidades dos clientes em qualquer lugar e a qualquer tempo;

- Contrato: Planos e estratégias são formados com o conhecimento e experiência de peritos e entre os membros da organização. $O$ gestor virtual prepara os contratos e define espaços a serem contratados temporariamente e infra-estrutura de comunicação estabelecidas. Os serviços e matéria-prima são procurados e as fontes de trabalho são identificadas;

- Produção: A produção real começa. Constantemente a organização virtual verifica a si própria para comparação entre o capital e os requisitos dos clientes e fornecedores, quando, então, as áreas de deficiência são observadas. Nada é estático. 
- Dissolução/Reconstituição: Depois de se desenvolver todo o processo, os especialistas são destituídos, os contratos pagos, o capital retornado e o cliente satisfeito. Essa fase é imprescindível pois após um projeto ser finalizado outro poderá entrar em ação, o que poderá requerer que os recursos se adaptem aos novos requisitos. A organização tem a chance de tornar-se uma entidade que aprende testemunhando seus próprios erros objetivamente e toma atitudes corretivas para finalizar um processo errôneo, como por exemplo, eliminando um contratante de uma lista de fornecedores preferenciais ou estudar a concorrência. Novas dinâmicas são construídas com novos parceiros.

O processo básico da organização virtual está diretamente relacionado com o ciclo de vida da mesma, calcado em um modelo de gestão especializado. De fato, não há definido um processo específico, pois as atividades são ad-hoc e necessitam de adequação aos produtos e serviços que devem ser executados para atingir os objetivos estratégicos daquele momento específico. Agustini (2000) resume bem esse caráter evolutivo quando explica o devir de uma organização virtual: "Tornar-se uma organização virtual é um processo evolutivo de ações e reações de projeto e gerenciamento no desenvolvimento de um ambiente de negócios, bem como nos objetivos e no comportamento das empresas participantes".

Decorre dessa definição que os processos de negócio que sofrem evolução são os processos internos de cada empresa participante. E existe um delineamento das tarefas principais do processo inter-organizacional. Por isso a necessidade de um modelo de gestão da organização virtual, pois:

Um processo inter-organizacional deve ser projetado e gerenciado de forma conjunta pelas organizações envolvidas em sua execução, ou seja, deve ser visto como um processo em rede. Esse novo enfoque representa um grande desafio em termos de gestão. A organização virtual está apta a se reconfigurar e alocar recursos para a execução de uma tarefa ou meta, uma única vez ou diversas vezes. A tarefa proposta é decomposta em diversas sub-tarefas, executadas paralelamente por parceiros, possibilitando assim maior agilidade e independência entre processos.(TOLEDO e LOURES, 2006). 
Agustini, apud Oliveira, (2000) descreve um modelo de gestão básico para as organizações virtuais (ilustração 3):

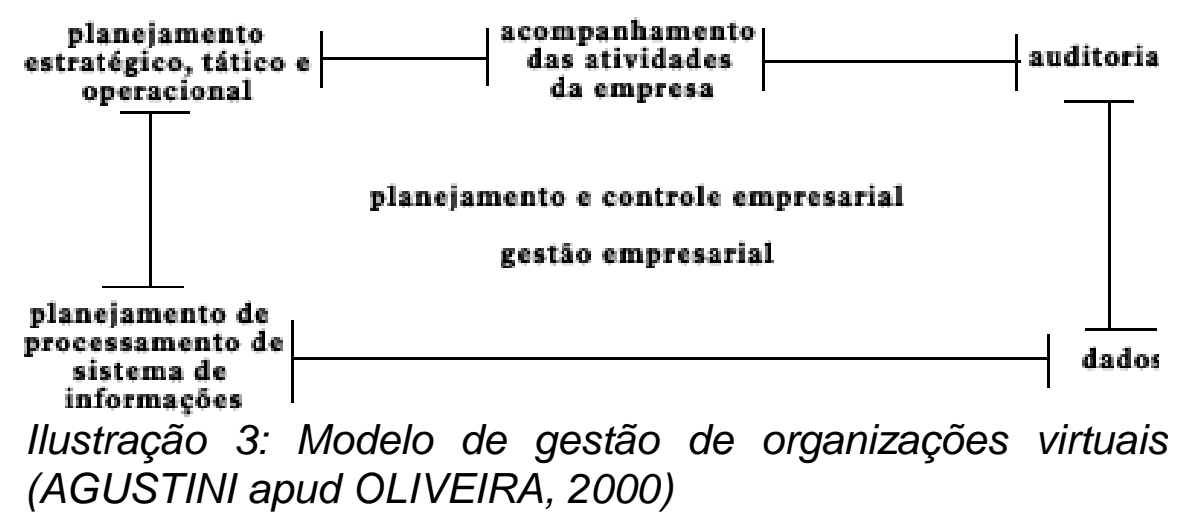

A ilustração 3 descreve que para um efetivo planejamento, controle e gestão empresarial é necessário realizar o planejamento estratégico, tático e operacional da organização aliado ao uso de processamento em sistemas de informações que processam os dados coletados. Também decorre reformulações do planejamento estratégico a partir do acompanhamento das atividades da empresa e dos processos de auditoria que podem encontrar gargalos e defeitos no processo, assim, retroalimentando os dados a serem reprocessados e auxiliando na reformulação das estratégias.

Quando se pensa em gestão organizacional é natural expandir o conceito para a governança, pois o que fica na organização virtual são as diretrizes e políticas de comunicação e inter-operação entre as empresas. Dessa forma, a efetividade dos relacionamentos entre participantes:

[...] depende de um novo paradigma de governança, inspirado nos movimentos de código aberto e de regras claras e preestabelecidas - apoiadas em mecanismos de precificação e em atributos técnicos pré-configurados - de segurança, auditoria, avaliação de desempenho e pagamentos.(PITASSI e MACEDO-SOARES, 2003).

Essas definições estão alinhadas com o modelo de gestão e ciclo de vida da organização virtual apresentados por Agustini (2000). As citações de Heide (1994) e Ghosh e John (1999) apresentadas por Pitassi e Macedo-Soares (2003) exprimem bem essa idéia: 
"Como observa Heide (1994), governança é fenômeno multidimensional que envolve o início, o término e a manutenção dos relacionamentos entre um conjunto de partes independentes. [...] À medida que os relacionamentos interorganizacionais são vistos cada vez mais a partir de uma perspectiva estratégica e dinâmica, passa a prevalecer o uso da governança relacional, cujo princípio unificador é o compartilhamento de valores, desenvolvidos em contexto interpessoal (Ghosh e John, 1999)". (PITASSI e MACEDO-SOARES, 2003).

\subsection{Impactos na cultura organizacional}

Conforme já citado anteriormente as relações pessoais são minimizadas em um ambiente virtualizado. Dessa forma, as empresas que pretendem passar a adotar algum mecanismo de virtualização devem estar cientes de que deverão envolver esforços para mudar a cultura organizacional, pois, segundo Pitassi e MacedoSoares (2003): “A mudança de protocolo cultural provavelmente se configure no maior desafio em direção à virtualidade, já que ela envolve modelos mentais, cuja alteração é lenta e complexa."

Um quesito importante a ser observado pelos gestores virtuais no que tange a cultura organizacional é o tratamento da confiança, pois:

a convivência próxima e constante propicia condições mais favoráveis à criação, fortalecimento e manutenção de relações de confiança do que as relações virtuais; e a confiança é um dos fatores fundamentais para a disseminação do conhecimento tácito. (SAKUDA e VASCONCELOS, 2005).

Se não houver confiança na disseminação do conhecimento e informações, a organização virtual tenderá ao fracasso, pois, ela está fortemente relacionada com fluxo de informação e a comunicação entre os participantes. Por esse motivo, podese afirmar que os participantes em uma organização virtual devem aprender a ter confiança nos processos inter-organizacionais uma vez que cada parceiro depende fortemente da execução de atividades de outros parceiros, mas não dos parceiros em si. Dessa forma,

se 0 relacionamento virtual habilita 0 afastamento físico e os encontros momentâneos, a complementaridade derivada da especialização faz com que 
cada firma passe a depender cada vez mais das outras, sem que seja necessário que essa dependência se restrinja a parceiros fixos e conhecidos.(PITASSI e MACEDO-SOARES, 2003).

\subsection{Valor do consumidor}

Um tópico interessante para este trabalho é a condição do consumidor como proporcionador de valor ao processo da organização virtual. Pois, é a partir das reações do consumidor que a empresa irá se moldar para atender melhor suas necessidades. Outro fato importante é que comportamentos, críticas e idéias dos consumidores podem levar a organização a novos produtos e até delinear melhor novos mercados. Esse argumento é sintetizado por Pitassi e Macedo-Soares (2003) quando afirmam que a cadeia de valor é o conjunto separado, porém interligado, de atividades por meio das quais uma empresa cria e comercializa seus produtos e serviços. Leão e Mello (2001) explicam que os consumidores traduzem atributos de produtos em benefícios (ou conseqüências de uso) que estes produzem. Desse modo, a visualização do produto pelo cliente é um impacto no modo como ele percebe a realidade em que vive e isso altera sua forma de pensar. É por esse motivo que:

Os constructos de percepção descritos no mapa hierárquico de valor construído a partir dos níveis de abstração dos consumidores, podem ser usados como base para o desenvolvimento de estratégias que irão criar apelos ao consumidor através das orientações particulares de produtos.(LEÃO e MELLO, apud Reynolds e Gutman, 2001).

Hasse (2006) citando Franke (2002) resume bem a diferença entre empresas tradicionais e empresas virtuais quanto ao valor do consumidor para cada uma delas:

[...] enquanto as empresas tradicionais buscam por clientes e mercados para seus produtos, o gestor (virtual) analisa o comportamento do consumidor e faz o contrário, cria produtos para clientes e mercados com necessidade deste produto. Esta forma particular de gerenciamento é chamada de meta- 
gerenciamento, que é o gerenciamento de uma tarefa virtualmente organizada. (HASSE, 2006).

Dessa forma, as organizações virtuais se beneficiam cada vez mais dos retornos dos clientes pois elas são projetadas para se adequar e se moldar às necessidades destes. Isso cria um cenário de alta competitividade, eficiência e qualidade dada as características das organizações virtuais de se reorganizarem para atender efetivamente os objetos estratégicos propostos para um determinado tarefa ad-hoc. 


\section{MÉTODOS E TÉCNICAS DE PESQUISA}

\subsection{Tipo e descrição geral da pesquisa}

A pesquisa foi de caráter exploratório buscando referências nacionais para o uso da virtualidade em organizações do tipo multidisciplinares. $O$ presente estudo estabeleceu uma pesquisa de âmbito nacional com algumas empresas desenvolvedoras de jogos eletrônicos existentes que, em sua maioria, constam no cadastro da Associação Brasileira das Desenvolvedoras de Jogos Eletrônicos (ABRAGAMES, http://www.abragames.org/). A ABRAGAMES é uma associação sem fins lucrativos que tem o objetivo de fortalecer a indústria nacional de desenvolvimento de jogos e nela possuem informações sobre contato de várias empresas desenvolvedoras de jogos as quais poderão ser enviados eletronicamente os questionários com questionamentos quantitativos e qualitativos.

A idéia principal dessa pesquisa é avaliar se essas empresas que dependem de equipes multidisciplinares utilizam algum mecanismo de virtualização e como o uso desses mecanismos impactam em seus processos e estruturas. Por esse motivo o contato foi realizado apenas por meio virtual (contato via e-mail).

As variáveis mais importantes para o estudo e que deverão ser consideradas na confecção do questionário quantitativo-qualitativo são:

- De natureza quantitativa:

- Caracterização da empresa (quantidade de funcionários, porte, principais atividades e mercado);

Ausência ou presença de processos organizacionais para utilização de mecanismos virtuais;

- Ausência ou presença de estruturas físicas ou tecnológicas que tornam a empresa capaz de usufruir da virtualidade;

As formas de interação entre as equipes multidisciplinares;

As formas de comunicação entre clientes e fornecedores; 
- De natureza qualitativa:

- Aspectos culturais da organização que ajudam ou atrapalham o processo de virtualização;

- Opinião das empresas acerca das vantagens obtidas e esperadas com o uso da virtualização;

Zanella (2006) explica, para o caso das pesquisas quantitativa, que as mesmas têm finalidade medir relações entre as variáveis. Ainda segundo Zanella apud Godoy (2006) é pela perspectiva qualitativa que "um fenômeno pode ser melhor compreendido no contexto em que ocorre e do qual é parte integrada", permitindo "captar" o fenômeno em estudo, a partir das perspectivas das pessoas nele envolvidas. Dessa forma, um questionário misto qualitativo-quantitativo tem o objetivo principal de captar, além do dado estatístico, principalmente as perspectivas das pessoas que trabalham em uma organização virtual ou com mecanismos virtuais.

O relacionamento entre as variáveis ajudaram a estabelecer e subsidiar respostas para a questão do uso da virtualidade nas empresas nacionais. Nesse sentido a pesquisa é causal e permitirá estabelecer conceituações mínimas para o uso da virtualização em equipes multidisciplinares no cenário nacional.

Os dados, de natureza primária, foram coletados diretamente na fonte através de questionário quantitativo-qualitativo.

\subsection{Caracterização da organização, setor ou área do objeto de estudo}

Esse trabalho se concentrou em um mercado em ascensão no Brasil, o de jogos eletrônicos. Essas empresas utilizam-se de equipes multidisciplinares e por trabalharem diretamente com tecnologia possuem fortes indícios do uso de mecanismos de virtualização. Dessa forma pôde-se caracterizar as organizaçõesalvo como:

\begin{tabular}{|c|l|}
\hline Associação & ABRAGAMES \\
\hline Tipo da organização & Indústria de desenvolvimento e publicação de jogos \\
\hline
\end{tabular}




\begin{tabular}{|c|l|} 
& eletrônicos \\
\hline Porte & Variável \\
\hline Setor & Terciário \\
\hline Área & Tecnologia da informação \\
\hline
\end{tabular}

\subsection{População e amostra}

O estudo realizado se deu através do contato com um conjunto de empresas desenvolvedoras de jogos interessadas, sendo em sua maioria, cadastradas no site da ABRAGAMES. Isso representa apenas uma amostra do mercado brasileiro pois nem todas as empresas desenvolvedoras de jogos existentes se manifestaram para participação dessa pesquisa pois não responderam ao primeiro contato em meio eletrônico, nem aos 3 contatos posteriores para participação. Segue abaixo a lista das que participaram da pesquisa e suas respectivas informações de contato.

\begin{tabular}{|c|c|c|}
\hline Empresa & Contato & UF \\
\hline Behold Studios & Site: http://www.beholdstudios.com.br/pt/ & DF \\
\hline Decadium Studios & Site: http://www.decadium.com/contact/ & RS \\
\hline Ilusis & $\begin{array}{l}\text { Site: http://www.ilusis.com/ } \\
\text { E-mail: contato@ilusis.com }\end{array}$ & MG \\
\hline Interama & Site: http://www.interama.net/ & $\mathrm{SP}$ \\
\hline Keeplay & $\begin{array}{l}\text { Site: http://www.keeplay.com/ } \\
\text { E-mail: keeplay@keeplay.com }\end{array}$ & MG \\
\hline Mother Gaia & Site: http://www.mothergaia.com.br/ & $\mathrm{SP}$ \\
\hline Musigames & $\begin{array}{l}\text { Site: http://www.musigames.com.br/ } \\
\text { E-mail: games@musigames.com }\end{array}$ & $\mathrm{PE}$ \\
\hline Sioux & Site: http://www.sioux.com.br/ & $\mathrm{SP}$ \\
\hline Webcore & $\begin{array}{l}\text { Site: http://www.webcoregames.com.br/ } \\
\text { E-mail: contato@webcoregames.com.br }\end{array}$ & SP \\
\hline
\end{tabular}




\subsection{Instrumento de pesquisa}

A pesquisa utilizou um questionário que possui aspectos quantitativos e qualitativos. Um esboço desse questionário está declarado no apêndice $\mathrm{A}$ deste projeto.

A parte quantitativa visa fornecer dados estatísticos das empresas e seu perfil básico no cenário nacional. Já a parte qualitativa visa capturar aspectos mais subjetivos que fazem parte do cenário da empresa específica.

Todos os dados capturados serão dados primários uma vez que as empresas serão as fontes respondentes do mesmo.

\subsection{Procedimentos de coleta e de análise de dados}

Primeiramente as empresas foram contatadas para marcar disponibilidade da execução do questionário. Depois, a coleta dos dados foi realizada através da emissão de um questionário em documento eletrônico para cada empresa listada na seção 3.3. Após o retorno das respostas foram iniciados os procedimentos de análise de dados que levaram em conta três métodos.

Método comparativo: Segundo Lakatos (1991) é um método criado por Tylor para estudar as semelhanças e diferenças entre diversos tipos de grupos e sociedades. Ele será empregado para comparar as empresas em tempo presente quanto às suas equivalências e diferenças.

Método Estatístico: Segundo Lakatos (1991) é um método planejado por Quetelet que permitem obter, de conjuntos complexos, representações simples e constatar se essas verificações simplificadas têm relações entre si. Dessa forma, os dados do questionário serão cruzados de modo a levantar as características principais de organizações multidisciplinares no âmbito de seus processos e estruturas para virtualização.

Método funcionalista: Segundo Lakatos (1991) é um método utilizado por Malinowski que permite a interpretação da sociedade levando em conta a função de suas unidades. Esse método auxiliará no entendimento dos questionamentos qualitativos no âmbito das empresas podendo criar mecanismos para traçar modelos 
abstratos e suas representações através dos exemplos advindos das experiências das empresas. 


\section{RESULTADOS E DISCUSSÃO}

\subsection{Caracterização das empresas entrevistadas}

A pesquisa revelou que a maioria (88,89\%) das empresas entrevistadas possuem uma administração profissional, sendo que todas as entrevistadas são empresas de pequeno porte com um corpo funcional de até 30 funcionários, o que era esperado para um mercado emergente nessa área como é o mercado brasileiro. Cerca de $88,89 \%$ das empresas utilizam-se de mão-de-obra especializada em regime CLT e todas possuem funcionários alocados localmente, ou seja, os contratados trabalham em um escritório regional da empresa. Esse fato indica que a equipe não é constituída para um projeto específico o que exprime o compromisso com custos fixos da equipe local.

Um fato interessante é que algumas empresas utilizam tecnologia nacional e atualizada para desenvolver seus produtos (cerca de 22,22\%) e as outras (cerca de $77,78 \%$ ) utilizam tecnologias estrangeiras e atualizadas. Nenhuma empresa, apesar do pequeno porte, está utilizando tecnologias antigas (defasadas em mais de 2 anos) o que sugere um processo de constante otimização de seus parques tecnológicos. A finalidade dos produtos das empresas se concentra em educação $(22,22 \%)$, propaganda (33,33\%) e entretenimento $(44,44 \%)$. Como as empresas estão no ramo do entretenimento digital, era esperado que a maior parte das empresas criassem produtos com esse propósito. Finalmente um aspecto muito importante é que grande parte das empresas $(66,66 \%)$ trabalham principalmente com um público de pessoas jurídicas, denotando que seus clientes são outras empresas que necessitam de produtos digitais de entretenimento ou propaganda para envolver seus consumidores. Em resumo então o perfil geral das empresas entrevistadas é:

- Empresas profissionais de pequeno porte;

- Possuem mão-de-obra especializada que trabalham localmente; 
- O regime de contrato de trabalho com os funcionários é predominantemente CLT;

- Trabalham principalmente com propaganda e entretenimento;

- Seus principais clientes são pessoas jurídicas;

\subsection{Aspectos de interação entre empresas}

A pesquisa revelou que as empresas formam parcerias constantes em seus projetos, sendo que $22,22 \%$ são contratos ocasionais que dependem do projeto em que estão trabalhando, $44,44 \%$ são contratos freqüentes com os mesmos parceiros e 22,22\% são contratos freqüentes com parceiros diferentes.

Outro fator é que a maioria das entrevistadas (55,56\%) possuem o conhecimento intra-organizacional concentrado em um único profissional (ou em um grupo de profissionais especialistas), sendo que esse conhecimento não é registrado em processos. Esse fato, não é interessante para a virtualização organizacional uma vez que não registra lições aprendidas nos processos intra-organizacionais e dificulta a formação de parcerias com outras empresas. Entretanto $33,33 \%$ das empresas incorporam o conhecimento inter-organizacional em seus processos internos e realizam atualizações e cerca de $11,11 \%$ avaliam as lições aprendidas em contratos periódicos. Esses $44,44 \%$ denotam empresas preocupadas com a dinâmica das relações entre as parceiras o que pode levar à configuração de cenários propícios à novas parcerias.

A grande maioria das empresas entrevistadas $(77,78 \%)$ realizam um contato direto com as parceiras. Cerca de $11,11 \%$ utilizam um plano de comunicação padrão e os $11,11 \%$ restantes criam um plano de comunicação especializado a partir de normas ou guias estabelecidos nos processos organizacionais.

Essa estatística denota que as empresas possuem a necessidade de formar contratos com parceiras, porém, apesar de mais da metade não registrar conhecimentos inter-organizacionais e, apesar de, praticamente metade achar importante guardar esse conhecimento, seja em lições aprendidas ou incorporação em seus processos internos, elas continuam a realizar, em sua maioria, contatos diretos com as parceiras o que as leva a, principalmente, realizar contratos com os mesmos parceiros cujo conhecimento inter-organizacional já é costumeiro. A 
estatística mostra que $22,22 \%$ dos contratos são ocasionais e que $44,44 \%$ são contratos realizados com os mesmos parceiros mostrando uma certa resistência das empresas, em geral, em se aventurar com parceiros novos e que poderiam auxiliar na diminuição de custos. Dessa forma, as empresas entrevistadas não poderiam ser classificadas como empresas virtuais em estágio 2, conforme síntese do trabalho de Toledo e Loures (2006), uma vez que seus processos estão ainda em fase embrionária de catalogação e não poderiam ser efetivamente terceirizados, independente de parceiros para a realização desse processo.

\subsection{Estruturas físicas ou tecnológicas que permitem usufruir da virtualidade}

As entrevistadas possuem uma boa estrutura tecnológica, como segue:

- $100 \%$ utilizam e-mail como forma de comunicação;

- $55,56 \%$ utilizam-se de recursos de teleconferência;

- $77,78 \%$ utilizam-se de sistemas de mensageira;

- $66,67 \%$ utilizam-se de redes sociais;

Os mecanismos de comunicação são muito importantes para 0 aproveitamento da virtualização organizacional, uma vez que, não existe o contato direto entre as partes. Esses dados indicam que as empresas estão buscando se expor mais em termos comunicativos o que permite uma interação melhor com parceiros, clientes e fornecedores.

Entretanto a pesquisa também revelou que:

- $66,67 \%$ não utilizam videoconferência;

- $77,78 \%$ não utilizam um ambiente virtual corporativo;

- $100 \%$ não utilizam wiki;

Nesse caso, a videoconferência e o ambiente virtual corporativo seriam ferramentas muito importantes para a comunicação entre os parceiros. Um ambiente virtual corporativo, favoreceria a implantação de redes virtuais estratégicas e ampliariam as capacidades da empresa, em termos de se conectar aos parceiros de uma forma mais efetiva. A não utilização do Wiki também denota que as empresas, em geral, não estão se preocupando muito com lições aprendidas nos seus 
processos internos, uma vez que, o uso do Wiki representaria uma forma de registrar conhecimento obtido e torná-lo facilmente acessível para sues colaboradores.

A pesquisa mostra um enquadramento das empresas entrevistadas, segundo a classificação sintetizada por Toledo e Loures (2006), como empresas virtuais de estágio 1, uma vez que na questão de conhecimento virtual não poderem ser classificadas como de estágio 2 justamente por não se utilizarem de ambientes virtuais corporativos e Wikis.

\subsection{Interação entre as equipes multidisciplinares}

Foi constatado que os gerentes de projeto da maioria das empresas $(55,56 \%)$ tratam diretamente com equipes multidisciplinares internas à empresa. $\mathrm{Na}$ outra parcela das empresas $(44,44 \%)$ esses gerentes trabalham com os técnicos internos e com os colaboradores de parceiros ou terceirizados. Também foi constatado que a maioria das empresas $(77,78 \%)$ realizam acordos com os parceiros de outras áreas da produção de jogos para um projeto específico, delineando os papéis de cada um. Esses itens identificam que grande parte das empresas está apta a trabalhar com equipes multidisciplinares. Entretanto, como 100\% delas possuem uma modalidade de trabalho local, essas organizações podem não possuir know-how suficiente para lidar com equipes geograficamente separadas, principalmente por que também não atualizam seus processos inter-organizacionais.

Conforme exposto no item 4.3 as empresas possuem uma predominância da utilização de recursos tecnológicos em sua infra-estrutura que segundo Cunha e Medeiros (2007) mencionando Pinochet, Barbosa e Silva (2005) são importantes para viabilização de redes colaborativas inter-organizacionais. No entanto, conforme exposto nessa análise as empresas entrevistadas estariam em estágio embrionário, pois utilizaram esses recursos internamente com suas equipes locais. 


\subsection{Aspectos de comunicação com os clientes}

Como os principais clientes das entrevistadas são pessoas jurídicas e governo $(77,78 \%)$ elas não necessitam utilizam de panfletagem para divulgar seus trabalhos. Também, a grande maioria $(66,67 \%)$ não se utilizam de propaganda para divulgação, e $88,89 \%$ das entrevistadas utilizam e-mail com a principal forma de comunicação. Cerca de $44,44 \%$ usam redes sociais e $55,56 \%$ comunicam-se diretamente com os clientes, denotando a necessidade de interação maior com 0 cliente para obter feedbacks. Como a maioria se comunica diretamente com os clientes não seria necessário, de fato, realizar propagandas. Esse quesito é importante por que demonstra a utilização do meio virtual para reduzir seus custos com divulgação o que é uma vantagem que deve ser explorada cada vez mais em empresas virtualizadas. Utilizando a classificação de Toledo e Loures (2006), essa estatística classificaria as empresas no estágio 2 uma vez que seus produtos são especificações personalizadas de acordo com as necessidades dos clientes.

\subsection{Aspectos de comunicação com os fornecedores}

Das entrevistadas $88,89 \%$ não utilizam mala direta nem se utilizam de sistemas organizacionais integrados representando pouca integração tecnológica com os fornecedores. Porém, $66,67 \%$ se comunicam por e-mail e $77,78 \%$ realizam comunicação direta com os fornecedores o que denota uma dependência direta entre as partes participantes, isso indica que as relações entre a empresa e fornecedores são mais pessoais e eventualidades contratuais são sanadas por discussões contratuais e não mecanismos processuais pré-estabelecidos, bemdefinidos e que poderiam ser automatizados e virtualizados. 


\subsection{Processos organizacionais}

O gráfico 1 mostra a eficiência das empresas em termos dos processos organizacionais:

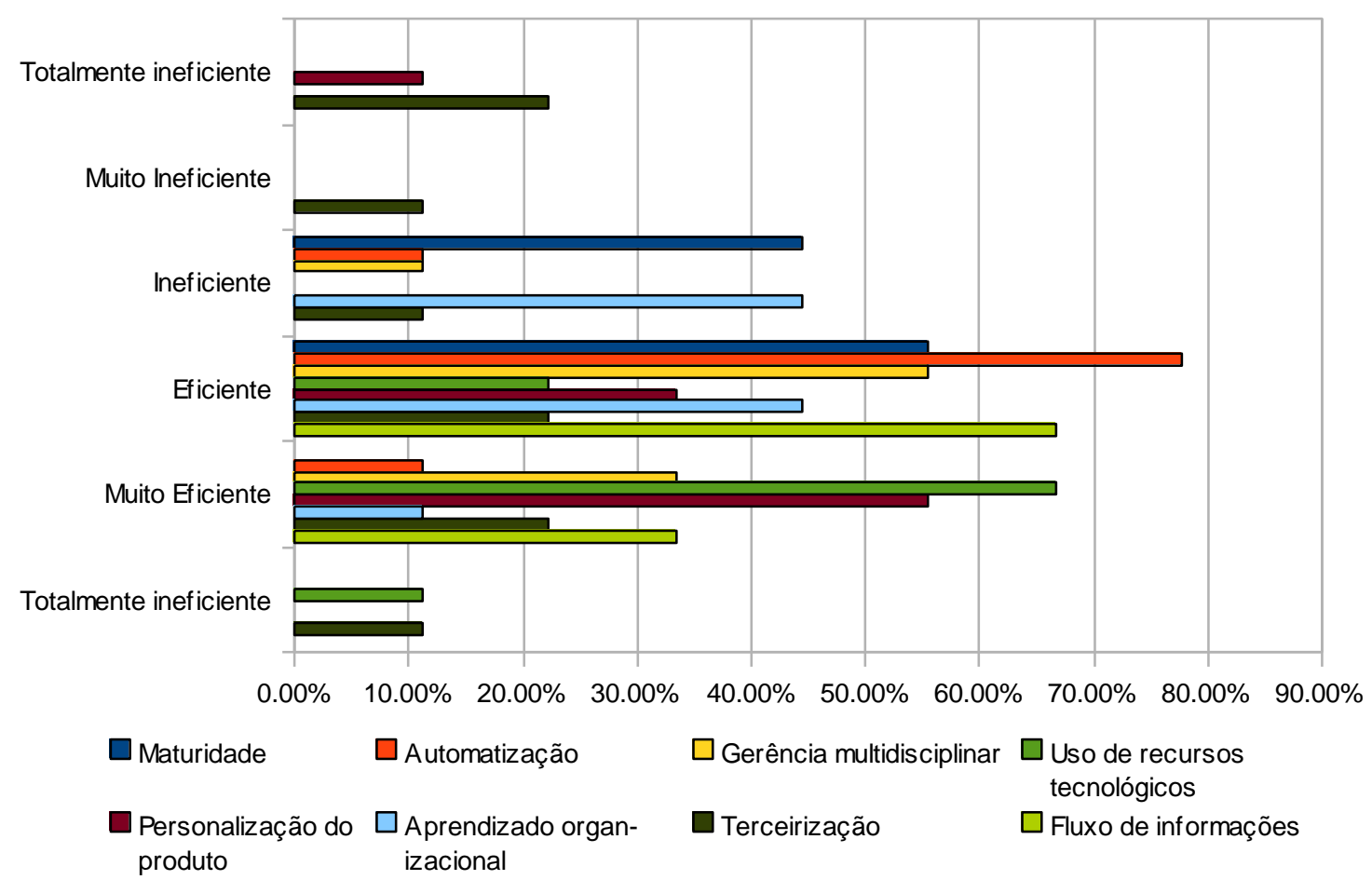

Gráfico 1: Maturidade das entrevistadas em termos de processos organizacionais

Esse gráfico mostra que, em geral, as entrevistadas se consideram eficientes em seus processos organizacionais muito embora hajam 44,44\% que ainda se consideram ineficientes em termos de maturidades dos processos.

Em relação à automatização gradativa dos processos, cerca de $77,78 \%$ das entrevistadas crêem ser eficientes, 11,11\% acreditam serem ineficientes e 11,11\% acreditam ser muito eficientes.

Quanto à gerência multidisciplinar 55,56\% acreditam ser eficientes e 33,33\% acreditam ser muito eficientes. Isso é esperado uma vez que as empresas trabalham com equipes de disciplinas diversas, logo elas devem ser eficientes ou muito eficientes nesse ponto. 
Já quando ao uso de recursos tecnológicos todas se consideram eficientes, distribuídas em $22,22 \%$ (eficientes), $66,67 \%$ (muito eficientes) e $11,11 \%$ (totalmente eficientes). Isso é importante, pois indicam uma forte uso de tecnologias da informação que são esperados por empresas que utilizam mecanismos de virtualização.

Como o mercado em que as entrevistadas estão inseridas necessita de muita personalização dos produtos cerca de $88,89 \%$ confirmam eficiência nesse quesito (33,33\% eficiente e $55,56 \%$ muito eficiente).

Com relação ao aprendizado organizacional existem $44,44 \%$ que se consideram ineficientes, $44,44 \%$ que se consideram eficientes e $11,11 \%$ que se consideram muito eficientes. Isso mostra que as entrevistadas possuem uma preocupação com o aprendizado, apesar de $44,44 \%$ não conseguirem registrá-lo corretamente.

A capacidade de realizar parcerias com terceiros através da terceirização ficou um pouco dividida entre: $44,44 \%$ que se consideram ineficientes em diversos graus e $55,55 \%$ que se consideram eficientes em diversos graus. O gráfico nos mostra um peso maior para o limite da eficiência total o que é bom. Empresas que querem usar mecanismos de virtualização estão também pensando em formas de diminuição de custos através de terceirização.

Finalmente, as entrevistadas se consideram eficientes quanto ao fluxo de informações e conhecimento na empresa, sendo $66,67 \%$ eficientes e $33,33 \%$ muito eficientes. Isso é confirmado pela boa estrutura tecnológica que as entrevistadas possuem.

As estatísticas apresentadas tendem à caracterização, segundo analisado a partir das sínteses de Toledo e Loures (2006), que as empresas entrevistadas estariam em um estágio 1 de virtualidade, pois estas em média apresentam uma tendência a valorizar o aprendizado organizacional e a utilizar os recursos de terceirização. 


\subsection{Perspectivas sobre os aspectos culturais da organização e opiniões acerca das vantagens obtidas e esperadas com o uso da virtualização}

O Diretor Criativo da Behold Studios, Saulo Camarotti, corrobora com o fato de que as empresas desenvolvedoras de jogos são ambientes propícios para virtualização, segundo ele: "o processo tecnológico de produção de jogos eletrônicos permite uma eficiente virtualização da empresa". Entretanto, ele também aponta para uma dificuldade no processo criativo pois depende do esforço humano, existindo uma fraca hierarquização de idéias quando as equipes são pequenas. Ele conta ainda que em equipes pequenas não é necessário burocratizar muito o processo, de tal forma que a virtualização entra como uma ferramenta de catalisação do processo produtivo. Dessa forma, a opinião de Saulo converge para as afirmações de Mello et al (2000) que explica que o investimento em tecnologia, a maior automação e flexibilidade de estruturas, contratos junto a pessoas passam a ser diferenciais importantes para a sustentação e crescimento das organizações no mundo moderno.

Adicionalmente, Fernando Costa, Sócio e Diretor Administrativo e Comercial da Keeplay, garante que colaboradores que não possuem maturidade e experiência o suficiente não podem atrapalhar na virtualização, uma vez que os mesmos não trabalhariam eficientemente à distância. Fernando Costa também, aponta para duas vantagens esperadas com a virtualização: o aumento da capacidade produtiva e a flexibilidade de trabalho. Essa opinião de Fernando Costa, corrobora a idéia de Pitassi e Macedo-Soares (2003) quando afirmam que a mudança de protocolo cultural provavelmente é o maior desafio em direção à virtualidade.

A Diretora Financeira, Sandra Albuquerque, da Musigames afirma que: "A virtualização permite que empresas de pequeno e médio porte consigam atingir mercados que não seriam possíveis em uma organização tradicional." Isso confirma a vantagem da virtualização dentro das empresas e corrobora a afirmação de Fernando Costa quando afirma que aumenta a capacidade produtiva de uma empresa. Também, Tiago Tex, Diretor Executivo da Interama, afirma que uma das vantagens é a "otimização de custos, que seriam melhores que contratação CLT" 
uma vez que a virtualização permitiria contratos mais flexíveis. Essas opiniões estão alinhadas com as afirmações de Cunha e Medeiros (2007) quando avaliam que os ambientes de trabalho virtuais são uma conseqüência das estruturas em rede, trazendo benefícios como aumento de produtividade, maiores lucros e diminuição de custos.

Fernando Bevilacqua, Sócio-fundador e Diretor de Projetos Web da Decadium, afirma que a maior vantagem da virtualização da empresa é a difusão da marca da empresa e dos produtos. Ele afirma também que:

[...] Se um jogador chegar até um de nossos jogos através de nossa "fachada" virtual, ele será automaticamente e involuntariamente convidado a conhecer o que temos a oferecer. Ele não se sentirá como alguém que foi fisgado por uma propaganda, mas sim alguém que encontrou um novo local para se divertir. (FERNANDO BEVILACQUA)

Isso denota o valor do cliente para a empresa e que o mesmo também está inserido no contexto de virtualização, corroborando as citações de Leão e Mello (2001) quando explicam que os consumidores traduzem atributos de produtos em benefícios (ou conseqüências de uso) que estes produzem.

Nas questões de cultura organizacional, Cesar Corregiari, Diretor de Marketing da Webcore, afirma que: "Acredito que as relações interpessoais, o comprometimento e a capacidade técnica ajudariam. O que atrapalharia seria a dificuldade inicial de adaptação, o espaço no cronograma e eventualmente limitações financeiras." Corroborando a dificuldade inicial da maturidade dos colaboradores conforme exposto por Fernando Costa da Keeplay.

Tulio Marques Soria, Diretor Executivo da Mother Gaia Studio, exprime que a virtualização interna de uma empresa que usa desenvolvimento ágil seria inviável pelo motivo da comunicação mais informal e próxima. O que seria difícil em um ambiente virtual. Ele menciona que para equipes pequenas que usam desenvolvimento ágil seria inviável até em termos de produtividade e dos prazos curtos dos projetos. Essa preocupação do Diretor Executivo da Mother Gaia Studio está relacionada à questão da confiança por conta do aspecto de informalidade, conforme preceituado por Sakuda e Vasconcelos (2005) quando afirmam que a convivência próxima e constante propicia condições mais favoráveis à criação de relações de confiança do que as relações virtuais. Porém aponta como vantagens principais: 
A vantagem advém do trabalho com parceiros e fornecedores externos a empresa, pois, estando nossa empresa em Bauru, interior de São Paulo e por maioria, todos nossos parceiros e fornecedores em São Paulo Capital, nós, através de ferramentas, trabalhamos com equipes externas a distância. A comunicação e 0 ganho de produtividade são afetados, entretanto, o menor ônus oriundos de viagens de deslocamento e até de ter que ter cede em São Paulo (que é algo caro) é compensado. (TULIO MARQUES SORIA).

Dessa forma, a diminuição com gastos logísticos é muito importante para as empresas que utilizam mecanismos de virtualização e a descrição feita pelo Diretor Executivo da Mother Gaia Studio está também alinha aos conceitos encontrados em Cunha e Medeiros (2007). 


\section{CONCLUSÕES E RECOMENDAÇÕES}

A pesquisa revelou que a indústria de jogos brasileira, ainda que em ascensão, é constituída por empresas que se preocupam com as questões de virtualidade pois percebem que esses mecanismos ajudam na redução de custos operacionais. Pôde-se constatar que o uso de mecanismos virtuais as auxilia principalmente nas questões de divulgação e logística, seja pela ampliação da comunicação com clientes e fornecedores, seja pela diminuição dos custos advindos de propaganda física. Identificou-se que as empresas entrevistadas são de pequeno porte, porém apresentam alguns indicações de virtualização pois se enquadram nas classificações de Toledo e Loures (2006) como: no estágio 2 do vetor de interação com o consumidor, no estágio 1 do vetor de suprimentos virtuais e no estágio 1 do vetor de conhecimento virtual. Isso define que essas organizações possuem estruturas básicas para usufruir da virtualidade. Porém, foi constatado que seus processos inter-organizacionais carecem de maior atenção quanto ao registro de suas experiências e otimização dos mesmos e por esse motivo só podem ser classificadas no estágio 1 quanto ao vetor de suprimentos virtuais e conhecimento virtual.

As empresas parecem promissoras na questão do uso dos mecanismos de virtualização nas equipes multidisciplinares, pois, apesar de suas equipes ainda serem locais e a gestão ser predominantemente sobre as equipes internas, elas possuem todo o ferramental para permitir agilização da comunicação como o uso de programas de mensageira, redes sociais, teleconferências e e-mail.

$\mathrm{Na}$ questão da cultura organizacional, existe uma preocupação com as relações de confiança nas equipes multidisciplinares e por conta disso acabam por aceitar o compromisso de manter custos fixos com a manutenção de uma equipe local. A mudança de cultura organizacional também é ainda um desafio por conta da maturidade e experiência dos profissionais que atuam na área. Dessa forma, o processo de constituição da empresa virtual, conforme exposto por Agustini apud Mickler (2000), não se aplica a essas empresas e por conseguinte o processo de dissolução não pode ser aplicado. Isso demonstra uma tendência da utilização de 
mecanismos virtuais mas ainda não as configura como organizações plenamente virtuais.

As vantagens obtidas com o uso de mecanismos virtuais são:

- Otimização de custos nas contratações de recursos;

- Minimização de gastos logísticos;

- Atingir mercados que não seriam possíveis com organizações tradicionais;

- Difusão da marca da empresa e de seus produtos;

- Permite e facilita o trabalho com parceiros e fornecedores externos;

As vantagens esperadas a partir do uso de mecanismos virtuais são:

- Catalisação do processo produtivo;

- Aumento da capacidade produtiva;

- Flexibilidade de trabalho;

Em suma, a indústria de jogos eletrônicos brasileira parece muito interessada na virtualização e nos mecanismos de comunicação virtuais, porém as empresas ainda se mostram tímidas a realizar parcerias de forma mais ad hoc pois a questão cultural ainda é um problema que dificulta o processo de constituição de uma organização virtual. $\mathrm{O}$ alvo das empresas entrevistadas está ainda na otimização de suas tarefas operacionais de forma a melhorar a eficiência das mesmas, reduzir os custos e sobretudo melhorar a comunicação entre seus fornecedores, parceiros e clientes. Como a questão cultural ainda é um desafio e o registro de processos inter-organizacionais ainda é uma intenção, não estariam preparadas para estabelecer uma organização virtual conforme proposto pelo modelo de ciclo de vida sugerido de Agustini apud Mickler (2000). Dessa forma, seria interessante realizar trabalhos futuros com alguma das empresas da pesquisa para verificar sua estrutura e organização processual de forma a propor ajustes que as levem a aprimorar seus mecanismos virtuais e explorá-los de forma mais eficiente. A pesquisa mostrou uma tendência nessas empresas e as mesmas poderiam ampliar seus negócios ao criar planos de ampliação da virtualidade.

Como a pesquisa estava relacionada à eficiência ou ao uso de mecanismos virtuais ficou limitada apenas àquelas empresas que atenderam aos contatos por meio virtual. Ainda assim, o estudo buscou verificar a tendência de estruturação da 
virtualização e constatou-se que essa tendência existe e que as empresas ainda estariam em um estágio inicial da virtualização não explorando-a com maior eficiência por conta das questões de mudança cultural, e por esse motivo é recomendável que novos estudos nessa área explorem mais:

- Os conceitos da virtualização, principalmente na questão do delineamento de um modelo formal para criação de organizações virtuais separando a empresa em um nível abstrato que poderá ser concretizado através da configuração das necessidades dos clientes;

- Mecanismos que auxiliem na mudança cultural, uma vez que é importante mudar a cultura organizacional para se utilizar a virtualização;

- E, avaliar a criação/dissolução de organizações virtuais à luz de projetos interorganizacionais.

Dessa forma, futuros retornos ao tema devem confirmar ou refutar a catalisação do processo produtivo, o aumento da capacidade produtiva, a redução de custos e a flexibilidade da organização a quaisquer projetos e a quaisquer equipes que possam formar para atender uma necessidade específica do cliente. 


\section{REFERÊNCIAS}

AGUSTINI, Anapatricia M. Vilha Di. Organização Virtual um novo paradigma organizacional para o século XXI. São Paulo: UniCamp, 2000. Disponível em: <http://www.ccuec.unicamp.br/revista/infotec/artigos/anapatr.html>. Acesso em: 16 mai. 2010.

BARROS, Raphael Lima Belém; ALVES, Carina Frota; RAMALHO, Geber Lisboa. Investigating the Communication Process in Multidisciplinary Game Development Teams. Rio de Janeiro: Simpósio Brasileiro de Sistemas Colaborativos, 2009. Disponível em: <http://www.uniriotec.br/ renata.araujo/ SBSC2009/data/3918a061.pdf>. Acesso em: 28 mar. 2010.

CUNHA, Julieta C.; MEDEIROS, Janann J. Redes sociais no desenvolvimento de inteligência competitiva. Pernambuco: Gestão.Org., v. 5, n. 3, set/dez, 2007. Disponível em: <http://www.ufpe.br/gestaoorg/index.php/gestao/article/view/182/ 164>. Acesso em: 28 mar. 2010

HASSE, Danilo. Modelo de Incubadora Virtual, utilizando a Teoria das Organizações Virtuais. Gramado: XXIV Simpósio de Gestão da Inovação Tecnológica, $2006 . \quad$ Disponível em: $<$ http://www.anpad.org.br/login.php?cod_edicao_subsecao=162\&cod_evento_edicao $=19 \&$ cod_edicao_trabalho=6353>. Acesso 28 mar. 2010.

LAKATOS, Eva Maria; MARCONI, Marina de Andrade. Metodologia Científica. 2. ed. São Paulo: Editora Atlas, 1991.

LEÃO, André Luiz M. de S.; MELLO, Sérgio C. B. Estratégias de comunicação através do conhecimento dos valores dos usuários: aplicação do modelo meccas para um jornal on-line,XXIV Congresso Brasileiro de Ciências da Comunicação. Campo Grande: XXIV Congresso Brasileiro de Ciências da 
Comunicação, 2001. Disponível em: <http://www.intercom.org.br/papers/nacionais/ 2001/papers/NP3LEAO2.PDF>. Acesso em: 28 mar. 2010.

MELLO, Alvaro; SARSUR Amyra M.; SANTOS, Silvio A. dos. O Modelo de Gestão virtual e o Teletrabalho: algumas práticas em empresa brasileira. São Paulo: Beca e-work, 2000. Disponível em: <http://beca-ework.com/artigos/Modelo de Gestão Virtual e o Teletrabalho.pdf>. Acesso em: 16 mai. 2010.

PITASSI, C.; MACEDO-SOARES, T. D. L. V. A. de. Redes estratégicas virtuais: fatores críticos de sucesso. Curitiba: Revista de Administração Contemporânea, 7(Edição especial), pp. 75-99, 2003. Disponível em: $<$ http://www.scielo.br/pdf/rac/v7nspe/v7nespa05.pdf>. Acesso em: 28 mar. 2010

SAKUDA Luiz O.; VASCONCELOS, Flávio de C. Teletrabalho: Desafios e Perspectivas. Bahia: O\&S, v.12 n. 33, 2005. Disponível em: $<$ ttp://www.revistaoes. ufba.br/include/getdoc. php?id=749\&article=626\&mode=pdf>. Acesso em: 28 mar. 2010.

TOLEDO, Luciano Augusto, LOURES, Carlos Augusto. Organizações Virtuais. São Paulo: Caderno Ebape, v. 4, n. 2, 2006. Disponível em: <http://www.trese.gov.br/servicos/biblioteca/BibliotecaVirtual/Livros/Organizacoes_virtuais_caderno s_ebape.pdf>. Acesso em: 28 mar. 2010.

ZANELLA, Liane Carly Hermes. Metodologia da Pesquisa. Florianópolis: Secretaria de educação a distância SEAD/UFSC, 2006. 


\section{APÊNDICES}

\section{Apêndice A - Questionário de pesquisa}

1. Caracterização da empresa (para cada questão selecionar apenas uma alternativa)

a) Qual o tipo de administração da empresa?

1. ( ) Familiar;

2. () Familiar e Profissional;

3. ( ) Profissional;

b) Qual a quantidade média de funcionários de sua empresa?

1. ( ) até 30 ;

2. () de 30 a 70 ;

3. () de 70 a 100 ;

4. () mais de 100;

c) Qual o tipo de mão-de-obra predominante na organização?

1. ( ) não especializada;

2. ( ) semi-especializada;

3. ( ) especializada;

d) Qual a modalidade de trabalho predominante adotada para os funcionários da empresa?

1. ( ) trabalho local;

2. ( ) trabalho à distância (em escritórios separados geograficamente);

3. ( ) home-office integral;

4. ( ) consultoria flexível (autônomos, free-lancers);

e) A mão-de-obra é composta predominantemente de:

1. ( ) funcionários contratados (CLT); 
2. ( ) funcionários contratados como pessoa jurídica;

3. ( ) freelancers;

4. ( ) terceirizados;

f) Em geral, qual o tipo de tecnologia mais utilizada na organização? (Obs.: desatualizada considerando a não atualização da tecnologia por um período de 2 anos)

1. ( ) nacional e desatualizada;

2. ( ) nacional e atualizada;

3. ( ) estrangeira e desatualizada;

4. ( ) estrangeira e atualizada;

g) Qual a finalidade principal dos produtos da organização?

1. ( ) educação;

2. ( ) propaganda;

3. ( ) simulação (engenharia/militar/etc..);

4. ( ) apenas entretenimento;

h) Qual o principal público da organização?

1. ( ) escolas;

2. ( ) governo;

3. ( ) pessoa física;

4. ( ) pessoa jurídica;

2. Processos organizacionais (Escala avaliativa de 0 a 5 , sendo 0 totalmente ineficiente e 5 totalmente eficiente).

\begin{tabular}{|l|l|l|l|l|l|l|}
\hline Questão & $\mathbf{0}$ & $\mathbf{1}$ & $\mathbf{2}$ & $\mathbf{3}$ & $\mathbf{4}$ & $\mathbf{5}$ \\
\hline Maturidade de processos organizacionais de sua empresa. & & & & & & \\
\hline Automatização gradativa de processos. & & & & & & \\
\hline Gerência de equipes multidisciplinares. & & & & & & \\
\hline
\end{tabular}


\begin{tabular}{|l|l|l|l|l|}
$\begin{array}{l}\text { Uso de recursos tecnológicos para comunicação entre } \\
\text { equipes. }\end{array}$ & & & & \\
\hline Processo de personalização de produtos. & & & & \\
\hline $\begin{array}{l}\text { Processo de retroalimentação de informações da empresa } \\
\text { por sugestões dos clientes, fornecedores, parceiros, entre } \\
\text { outros. (aprendizado organizacional) }\end{array}$ & & & & \\
\hline Terceirização de módulos de um determinado projeto. & & & & \\
\hline Fluxo de informação e conhecimento na empresa. & & & & \\
\hline
\end{tabular}

3. Sobre a interação entre empresas:

a) A formação de parcerias com outras empresas é:

1. ( ) rara;

2. ( ) ocasional, dependendo do projeto;

3. ( ) freqüente, em geral com os mesmos parceiros;

4. ( ) freqüente, em geral com parceiros diferentes;

b) O conhecimento inter-organizacional está:

1. ( ) concentrado em um profissional (ou grupo de profissionais) específico(s) da empresa (nesse caso, não registrado em processos);

2. ( ) atrelado apenas ao período da parceria com outras empresas sendo, em geral, esquecido;

3. ( ) atrelado apenas ao período da parceria com outras empresas e na dissolução do contrato são avaliadas as lições aprendidas;

4. ( ) incorporado nos processos da empresa como um todo e é atualizado caso haja uma nova situação;

c) Ao se comunicar com um parceiro de negócios:

1. ( ) é realizado um contato direto;

2. ( ) é criado um plano de comunicação padrão a ser seguido; 
3. ( ) é criado um plano de comunicação especializado a partir das normas ou guias estabelecidos nos processos inter-organizacionais;

4. Existência de estruturas físicas ou tecnológicas que permitem usufruir da virtualidade na organização.

a) Marque os mecanismos de comunicação mais utilizados na sua organização (poderá ser marcada mais de uma opção).

1. ( ) e-mail;

2. ( ) teleconferência;

3. ( ) videoconferência;

4. ( ) programas de mensageira (Msn, Gtalk, Skype, etc..);

5. ( ) ambiente virtual corporativo;

6. ( ) redes sociais (Buzz, Twitter, etc..);

7. ( ) wiki;

8. ( ) Outros. Quais?

5. Interação entre equipes multidisciplinares (Marcar apenas um item):

a) $\mathrm{O}(\mathrm{s})$ gerente(s) de projetos coordena $(\mathrm{m})$ diretamente:

1. ( ) Apenas colaboradores com perfil técnico internos da empresa;

2. () Colaboradores técnicos internos e de parceiros ou terceirizadas;

3. ( ) Colaboradores com perfil de gestão de outras empresas;

b) Se, em um projeto, existir parceria com outras empresas de diferentes áreas da produção de jogos, em geral, a parceira (pode-se considerar parceiros os free-lancers e as terceirizadas):

1. ( ) Se adéqua ao processo organizacional pré-estabelecido por sua empresa;

2. ( ) Chega-se a um acordo dos papéis de cada empresa;

3. ( ) A parceira impõe sua forma de trabalho;

6. Formas de comunicação entre clientes e fornecedores (poderá ser marcada mais de uma opção) 
a) A comunicação com o cliente se dá através de:

1. ( ) propagandas;

2. ( ) panfletagem;

3. ( ) e-mail;

4. ( ) redes sociais;

5. ( ) comunicação direta;

6. ( ) Outros. Quais?

b) A comunicação com os fornecedores se dá através de:

1. ( ) mala direta;

2. ( ) sistemas organizacionais integrados;

3. ( ) e-mail;

4. ( ) comunicação direta;

5. ( ) Outros. Quais?

7. Que aspectos culturais da organização ajudam(riam) ou atrapalham(riam) no processo de virtualização da empresa? (Subjetiva)

8. Quais as opiniões sobre as vantagens obtidas e esperadas com o uso da virtualização na sua empresa? (Subjetiva) 